\title{
Centralidade e emprego na região Nordeste do Brasil no período 1995/2007
}

\author{
Ana Carolina da Cruz Lima \\ Doutoranda em Economia do Cedeplar/UFMG \\ e bolsista CNPq \\ Rodrigo Ferreira Simões \\ Professor do Cedeplar/UFMG \\ e bolsista em produtividade do $\mathrm{CNPq}$
}

\begin{abstract}
Palauras-chave
economia do Nordeste, emprego, centralidade, desenvolvimento.
\end{abstract}

\section{Classificação JEL R11, R12,} C14.

Key words

Brazilian Economy;

Northeastern Region;

Employment; Central Place;

Urban Network; Development.

JEL Classification R11, R12, C14.

\section{Resumo}

A estrutura produtiva da região Nordeste do Brasil passou por uma série de transformações entre as décadas de 1950 e 1980, cujo resultado foi a instalação de um parque industrial complementar e dependente das áreas mais desenvolvidas do País. O objetivo do trabalho é identificar as microrregiões que atualmente desempenham papel central para o desenvolvimento da região e a dinâmica do emprego local, destacando inclusive a grande heterogeneidade existente nessa. Para sua consecução, são utilizados métodos descritivos e multivariados (ACP e clusters) na análise dos dados sobre o emprego e a diversidade local no período 1995/2007 (fontes: RAIS/MTE e IBGE). Os resultados demonstram que as microrregiões mais dinâmicas em termos de emprego também são aquelas que possuem os mais elevados índices de centralidade na região, que continua a apresentar profunda heterogeneidade intrarregional, apesar das melhorias nos últimos anos.

\section{Abstract}

The Brazilian economy in the northeastern region has undergone several changes between the 50's and 80's. The main result of those changes was the installation of an industrial park, which complements and depends on the most developed areas of the country. The purpose of the paper is to identify the areas that currently play a central role in the development of the region, the local employment dynamics, and the intra-regional heterogeneity. Descriptive and multivariate methods are used to analyze data on employment and local diversity in the period 1995/2007 (sources: RAIS/MTE and IBGE). The results show that the most dynamic areas in terms of employment are also those with the highest rates of centrality. Despite the improvements in recent years, intra-regional differences remain very high. 


\section{1_Introdução}

Quando se discute a questão regional no Brasil, o foco de análise é direcionado, naturalmente, para a região Nordeste, visto que essa (historicamente) apresenta indicadores econômicos e sociais bastante desfavoráveis em relação às áreas mais dinâmicas do País. Por esse motivo, tal região é o principal objeto dos estudos regionais, e, consequentemente, os principais planos de desenvolvimento elaborados pelas esferas federais de governo, ainda que escassos, têm como principal objetivo estimular a dinâmica econômica desse subespaço nacional.

No período que vai desde meados da década de 1950 até o início da década de 1980, a estrutura produtiva dessa região sofreu profundas transformações orientadas por grandes projetos de investimentos nacionais. Uma característica resultante desse processo foi o reforço da heterogeneidade dentro da própria região: observa-se a existência simultânea de áreas estagnadas, nas quais a modernização, quando ocorre, é bastante seletiva e limitada, e de áreas dinâmicas, cuja estrutura produtiva é bastante moderna e contribui significativamente para o desempenho da região como um todo. Esses contrastes dentro da região dão origem a vários "Nordestes", como evidenciado por Araújo (1995). Tal característica traz mais um fator de complexidade para a análise do desenvolvimento dessa região.

O objetivo do trabalho é identificar as microrregiões que atualmente desempenham papel central para o desenvolvimento do Nordeste, destacando inclusive suas grandes heterogeneidades. Para a consecução desse objetivo, é realizada uma análise da dinâmica do emprego na região, entre 1995 e 2007, e dos principais fatores determinantes da centralidade local em 2007.

Com o intuito de melhor contextualizar a discussão, um breve resumo sobre o desenvolvimento recente da economia do Nordeste é realizado na seção 2 . Na terceira seção, a dinâmica do emprego nas microrregiões nordestinas é analisada por meio de dois métodos descritivos: o cálculo de medidas de localização e de especialização e a análise Diferencial-Estrutural (shift-share). ${ }^{1} \mathrm{Na}$ seção 4, são utilizados métodos de análise multivariada (análise de componentes principais e de clusters) para caracterizar a centralidade no Nordeste brasileiro, destacando os principais aspectos teóricos sobre redes urbanas. Em seguida, são realizadas as considerações finais.

\section{2_Desempenho da economia do Nordeste no pós-Segunda Guerra Mundial}

Antes de analisar a dinâmica do emprego e a centralidade na região Nordeste do Bra-

\footnotetext{
Neste caso, a variável-base é o emprego, devido à maior disponibilidade de informações nos níveis de desagregação espacial e setorial desejados e à sua representatividade para medir o crescimento econômico (proxy). Todavia, essa variável apresenta algumas limitações, já que se refere apenas ao emprego no setor formal e não consegue captar o diferencial de tecnologia e de produtividade inter-regionais, além do fato de menor nível de emprego não implicar necessariamente menor produção industrial.
} 
sil, é importante realizar um breve resumo sobre seu desenvolvimento econômico recente, tendo como principal finalidade resgatar as alterações significativas ocorridas em sua estrutura produtiva, fornecendo, dessa forma, melhor compreensão do processo como um todo.

No final da década de 1950, as disparidades socioeconômicas observadas entre as regiões brasileiras, principalmente entre as regiões Sudeste (em rápido crescimento industrial) e Nordeste (estagnada), evidenciaram a importância da questão regional para o desenvolvimento de longo prazo do País. Para promover o desenvolvimento regional, foi criado, ainda no governo de Juscelino Kubitschek, o Grupo de Trabalho para o Desenvolvimento do Nordeste (GTDN), cujas propostas de políticas enfatizavam a importância da industrialização para a superação do subdesenvolvimento na região. O objetivo era criar no Nordeste um centro autônomo de expansão industrial mediante o incentivo às indústrias de base e àquelas que aproveitassem as matérias-primas locais, uma vez que o setor primário-exportador era incapaz de impulsionar o seu desenvolvimento.

A década de 1960 marca uma nova fase no desenvolvimento econômico dessa região: incentivos fiscais e financeiros (siste- ma 34/18 - Finor, etc.) estimularam o desenvolvimento das atividades urbanas e industriais, e o Nordeste começou a apresentar uma nova dinâmica, na qual a participação relativa do setor primário no PIB regional diminuiu, enquanto a participação dos setores secundário e terciário aumentou, com significativa melhoria e diversificação de seu parque industrial (a taxa média de crescimento industrial foi de $9 \%$ a.a.). O segmento industrial de produtos intermediários absorveu aproximadamente 60\% dos investimentos realizados pelo sistema de incentivos fiscais, aumentando sua participação no Valor da Transformação Industrial (VTT) da região de 16\% em 1960 para 41\% em 1975 (Guimarães Neto, 1989). Em contrapartida, a produção de bens de consumo não durável diminuiu sua participação de 83\% em 1960 para 48\% em 1975 (foi o segmento industrial que obteve o pior desempenho no período).

Essas mudanças reconfiguraram a estrutura produtiva industrial do Nordeste, que passou a apresentar duas características principais em relação à expansão da indústria nacional liderada pela região Sudeste:

a. dependência: nesse período, ocorreu a intensificação do processo de integração nacional, primeiro pelo comércio e depois pela trans- 
ferência de capitais produtivos da região central para a periferia. O resultado foi a reprodução das atividades industriais localizadas no Sudeste nas demais regiões do País, em particular no Nordeste. Como os recursos necessários à expansão industrial nessa região eram em geral extrarregionais, bem como seus principais fornecedores e consumidores, a continuidade de seu crescimento estava ligada ao bom desempenho da economia nacional, em especial da região Sudeste; e

b. complementaridade: o crescimento dos gêneros dinâmicos da indústria no Nordeste foi proporcionado por recursos do sistema de incentivos fiscais e financeiros, cuja origem era essencialmente extrarregional. Assim, havia uma tendência a maior complementaridade entre os segmentos industriais do Nordeste e do resto do País, especialmente da região Sudeste. Além disso, a busca por mercados consumidores extrarregionais evidenciava a posição de fornecedora de insumos para as demais regiões do País, concedendo a essa região uma no- va posição na divisão inter-regional do trabalho industrial no Brasil. Assim, a estrutura industrial do Nordeste se ajustou à estrutura nacional e passou a acompanhar seus movimentos cíclicos.

Outra característica dessa nova indústria foi seu elevado grau de concentração espacial: Bahia, Ceará e Pernambuco foram os Estados mais beneficiados por esse processo e possuíam aproximadamente $50 \%$ dos complexos industriais localizados na região, no final da década de 1980. Além disso, os níveis de emprego, produtividade e salários registrados nesses Estados eram os mais elevados da região (Lima e Lima, 2005).

Consideradas tais características, observa-se que desenvolvimento industrial da região Nordeste, no período pós-1960, ficou aquém das expectativas do GTDN, uma vez que foi uma industrialização tardia e complementar, com pequena difusão dos efeitos dinâmicos sobre a própria região. $\mathrm{O}$ seu desenvolvimento não contribuiu da maneira esperada para amenizar as disparidades interregional e intrarregional, já que a implantação de complexos industriais não gerou os impulsos necessários para a dinamização da economia local (sua natureza capital-intensiva limitou a criação de postos de trabalho adequada para a região, a retenção da 
renda gerada na própria região foi bastante limitada, etc.). O resultado foi uma indústria concentrada, pouco integrada internamente, com baixo nível de diversificação, elevado diferencial de produtividade, salários e emprego e pouco representativa quando comparada à indústria nacional (Lima e Lima, 2005).

É preciso salientar que as tendências de acumulação do setor privado foram em diversos momentos reforçadas pela ação estatal, o que deu origem a subespaços dotados de estruturas econômicas modernas, responsáveis, em parte, pelo desempenho relativamente positivo da economia regional (áreas de comportamento extremamente dinâmico, mesmo em períodos de crise da economia nacional). Esses subespaços são chamados de "polos dinâmicos", entre os quais se podem destacar o polo petroquímico de Camaçari, o polo têxtil e de confecções de Fortaleza, o complexo minero-metalúrgico de São Luís, o polo agroindustrial de Petrolina/Juazeiro, o polo de fruticultura irrigada do Vale do Açu, a área de agricultura de grãos nos cerrados do extremo Oeste baiano, Sul do Maranhão e do Piauí (microrregiões de Barreiras, Bom Jesus da Lapa e Gerais de Balsas), além dos polos tecnológicos do Recife e de Campina Grande. Mais recentemente, podem-se citar outras regiões com desempenho significativo em termos de emprego, como a fruticultura em Mossoró e as áreas de desenvolvimento endógeno nas microrregiões de Crato-Juazeiro do Norte-Barbalha (agroindústria, cana-deaçúcar e derivados), Catolé da Rocha, Seridó ocidental, Vale do Ipojuca e Alto Capibaribe (indústria têxtil), como evidenciado por Lima (2004). Simultaneamente, há subespaços estagnados na região (semiárido, zonas cacaueiras e canavieiras), nos quais a modernização é restrita e seletiva. A análise dessas diferenças intrarregionais permite identificar com mais clareza a heterogeneidade e a complexidade da economia regional.

Nessa perspectiva, pode-se falar, como destacado por Araújo (1997, p. 38), de vários "Nordestes", cada um com suas particularidades: "O Nordeste do oeste baiano e o Nordeste canavieiro do litoral do Rio Grande do Norte e de Alagoas, o Nordeste agroindustrial do sub-médio do São Francisco, o Nordeste cacaueiro do sul da Bahia, o Nordeste minero-metalúrgico e agroindustrial do Maranhão, o Nordeste semi-árido, etc.”. Além disso, é preciso destacar que mesmos os subespaços regionais dinâmicos podem funcionar como enclaves para a economia regional, uma vez que sua articulação interna pode ser extremamente fraca. 


\section{3_Dinâmica do emprego na região Nordeste: avaliação por métodos de análise descritiva}

\section{1_ Medidas de localização e de especialização}

Para analisar os padrões de crescimento econômico na região Nordeste, serão utilizadas, inicialmente, medidas de localização e especialização, de natureza descritiva e exploratória. ${ }^{2}$ Essas medidas serão calculadas a partir de duas matrizes de informação, com a distribuição do emprego por setores e microrregiões (base de dados RAIS/MTE) para os anos 1995 e 2007, cuja análise descreve os padrões de comportamento dos setores produtivos no espaço econômico (variações inter-regional e intrarregional). São definidas então as seguintes variáveis:

$E_{i j}=$ emprego no setor $i$ da região $j$,

onde $j$ representa cada uma das $187 \mathrm{mi}$ crorregiões analisadas (Fernando de Noronha não está incluída na análise), e $i=$ extrativa mineral, indústria de transformação, serviços industriais de utilidade pública, construção civil, comércio, serviços, administração pública e agropecuária. $E_{o j}=\sum_{i} E_{i j}=\begin{aligned} & \text { emprego em todos os } \\ & \text { setores da região } j .\end{aligned}$

$$
\begin{aligned}
& E_{i o}=\sum_{j} E_{i j}= \text { emprego no setor } i \mathrm{de} \\
& \text { todas as regiões. }
\end{aligned}
$$

$E_{o}=\sum_{j} \sum_{i} E_{i j}=$ emprego em todos os setores de todas as regiões.

O cálculo da distribuição percentual do emprego em cada região por setor e da distribuição percentual do emprego de cada setor entre regiões é dado, respectivamente, por:

$i_{j}^{e}=\frac{E_{i j}}{\sum_{i} E_{i j}}$,

onde $\sum_{i} i_{j}^{e}=1 \mathrm{e} i_{o}^{e}=\sum_{j} i_{j}^{e}$

$j_{i}^{e}=\frac{E_{i j}}{\sum_{j} E_{i j}}$,

onde $\sum_{j} j_{i}^{e}=1$ e $j_{o}^{e}=\sum_{i} j_{i}^{e}$

\subsection{1_ Medidas de localização}

Possuem natureza setorial e analisam a localização das atividades entre as microrregiões em estudo. Seu objetivo é identificar padrões de concentração ou dispersão espacial do emprego setorial em um dado período. São quatro as principais medidas de localização: $\cdots \cdot \cdots \cdot \cdots \cdot \cdot \cdot \cdots \cdot$

Estas medidas possuem limitações técnicas (resultados condicionados pelos processos classificatórios iniciais) e conceituais (são incapazes de gerar relações explicativas para os fenômenos observados). Contudo, são medidas extremamente úteis na fase inicial de estudo (Haddad et al., 1989). 
a. Quociente Locacional ( $\left.Q L_{i j}\right)$ : compara a participação relativa de uma microrregião no emprego em determinado setor em relação à participação relativa dessa microrregião no total do emprego da economia de referência (no caso a região Nordeste), permitindo assim a identificação da base regional e o potencial de exportação dos setores nas respectivas microrregiões. Sua principal limitação está relacionada à possibilidade de mascarar processos, já que sua dimensão é relativa (favorece pequenas localidades). Sua fórmula é descrita por:

3 Os primeiros estudos que utilizaram o $Q L_{i j}$ para caracterizar economias locais de acordo com sua base econômica utilizavam a unidade como valor de referência. Contudo, graças à disparidade existente entre as regiões brasileiras, é provável que o número de localidades com $Q L_{i j}>1$ seja bastante elevado, o que indica apenas a existência de diferenciação produtiva e não garante a concentração dessas atividades. Além disso, para escalas territoriais pequenas,

$Q L_{i j}$ sobrevaloriza qualquer

diferenciação interna,

mesmo em estruturas pouco

diversificadas; e o contrário

ocorre em escalas territoriais

mais amplas, ou seja, a intensa

diversificação interna

subvaloriza a importância dos setores que apresentam

indicadores pouco expressivos

(Crocco et al, 2003). Por esse

motivo, optou-se por definir

um corte superior um pouco mais elevado para o $Q L_{i j}$ no presente artigo.
$Q L_{i j}=\frac{E_{i j} / E_{o j}}{E_{i 0} / E_{o 0}}$

Segundo Simões (2005), se $Q L_{i j}>4$, há especialização produtiva, ou seja, a microrregião $j$ está mais especializada no setor $i$ do que o conjunto de todas as microrregiões em análise (no contexto regional, esse setor é mais importante para a microrregião em questão do que os demais); se $1 \leq Q L_{i j} \leq 4$, há indícios de especialização; se $Q L_{i j}<1$, não há especialização. ${ }^{3}$

Em ambos os períodos analisados, 1995 e 2007, o maior número de especialização produtiva é verificado nos setores extrativos minerais, agropecuários e da indústria de transformação (sem considerar o setor de administração pública), como pode ser observado na Tabela 1 a seguir. Houve uma variação negativa $(-6,59 \%)$ na quantidade de especialização produtiva setorial na região, impulsionada pela diminuição da importância relativa dos setores extrativos minerais, serviços industriais de utilidade pública, comércio e serviços em algumas microrregiões. Já os setores da indústria de transformação e agropecuários experimentaram um aumento de sua importância relativa em algumas microrregiões. 
Tabela 1_Região Nordeste: microrregiões com especialização produtiva $\left(Q L_{i i}\right)$ - 1995 e 2007

\begin{tabular}{|c|c|c|c|c|c|c|c|c|c|}
\hline & Ext. Min. & Ind. Transf. & Serv. Ind. UP & Const. Civil & Comer. & Serv. & Agrop. & AP & Total \\
\hline 1995 & 37 & 20 & 15 & 5 & 4 & 1 & 46 & 50 & 178 \\
\hline 2007 & 32 & 22 & 7 & 3 & 3 & 0 & 49 & 51 & 167 \\
\hline Var. (\%) & $(-15,63)$ & 9,09 & $(-114,29)$ & $(-66,67)$ & $(-33,33)$ & $(-100,0)$ & 6,12 & 1,96 & $(-6,59)$ \\
\hline
\end{tabular}

Fonte: Elaboração própria com base nos dados da RAIS/MTE

Não houve mudanças significativas em termos das microrregiões que apresentaram especialização produtiva no decorrer do período analisado, ou seja, em geral, as microrregiões que tinham alguma especialização em 1995 continuavam a apresentálas em 2007, com poucas exceções. Além disso, as microrregiões "especializadas" são justamente aquelas destacadas como as de maior dinamismo, tradicional ou mais recentemente, na região Nordeste por diversos autores (Lima, 1994 e 2004; Araújo, 1997), como, por exemplo, Imperatriz e Gerais de Balsas, no Maranhão; Alto Parnaíba, Campo Maior e Floriano, no Piaúi; Pacajus e Sobral, no Ceará; Mossoró e Vale do Açu, no Rio Grande do Norte; Araripina e Petrolina, em Pernambuco; Barreiras, Paulo Afonso e Juazeiro, na Bahia, etc. A especialização produtiva identificada nos setores extrativos minerais, da indústria de transformação e agropecuários em 2007 pode ser visualizada na Tabela A.1 do Apêndice. b. Coeficiente de localizacão do setor $i\left(C L_{i}\right)$ : analisa se a distribuição espacial do emprego em um determinado setor é semelhante à distribuição espacial do emprego da economia de referência e varia entre 0 e 1 . Quanto mais próximo de zero, mais a estrutura setorial regional é semelhante, ou seja, menor a concentração do setor em análise (o setor está distribuído regionalmente de forma semelhante ao conjunto de todos os setores). Quanto mais próximo de um, mais a estrutura produtiva regional é diferente, ou seja, maior é a concentração. Esse coeficiente permite identificar o grau de dispersão relativa das atividades econômicas e selecionar aquelas que teriam menor tendência à concentração espacial. Em outras palavras, o $C L_{i}$ indica em quais setores in- 
vestir para diversificar a economia de referência. A principal limitação desse coeficiente é não considerar que pode haver distorção na distribuição do emprego.

$$
C L_{i}=\frac{\sum_{j}\left(\left|j^{e i}-j^{e o}\right|\right)}{2}
$$

sendo que $0 \leq C L_{i} \leq 1$

No caso da região Nordeste, observa-se que os setores que estão distribuídos regionalmente de forma semelhante ao conjunto do emprego em todos os setores são os de comércio, serviços, administração pública, serviços industriais de utilidade pública, construção civil e indústria de transformação, nos dois períodos analisados (1995 e 2007). Em outras palavras, o padrão de concentração regional desses setores é relativamente baixo, o que indica a importância de investir neles, em especial na indústria de transformação dada sua capacidade de gerar efeitos de encadeamento para trás e para frente - no caso da região Nordeste, a menos dinâmica do País, as recomendações de políticas indicam que sejam priorizados os efeitos de encadeamento para trás (Hirschman, 1958). Já nos setores extrativos minerais e agropecuários, cuja produção depende fortemente das fontes de matériasprimas, a dispersão espacial do emprego é relativamente baixa. Todavia, é preciso destacar que houve uma piora nesses coeficientes entre 1995 e 2007, inclusive para a indústria de transformação, o que pode gerar mais dificuldades para o desenvolvimento futuro das microrregiões em análise (Tabela 2).

c. Coeficiente de Associação Geográfica entre os setores i e k $\left(C A_{i k}\right)$ : compara a distribuição relativa do emprego nos setores $i$ e $k$ entre as microrregiões. Desta forma, ele permite identificar se a distribuição espacial do emprego em determinado

Tabela 2_Região Nordeste: coeficiente de localização setorial $\left(C L_{j}\right)$ - 1995 e 2007

\begin{tabular}{l|c|c|c|c|c|c|c|c} 
& Ext. Min. & Ind. Transf. & Serv. Ind. Up & Const. Civil & Comer. & Serv. & Agrop. & Ap \\
\hline 1995 & 0,610 & 0,265 & 0,196 & 0,219 & 0,139 & 0,172 & 0,543 & 0,181 \\
\hline 2007 & 0,548 & 0,272 & 0,260 & 0,215 & 0,107 & 0,207 & 0,563 & 0,151 \\
\hline Var. (\%) & $(-11,31)$ & 2,570 & 24,62 & $(-1,86)$ & $(-29,91)$ & 16,91 & 3,550 & $(-19,87)$
\end{tabular}

Fonte: Elaboração própria com base nos dados da RAIS/TEM. 
setor é semelhante à distribuição espacial do emprego nos demais setores. Esse coeficiente varia entre 0 e 1. Quanto mais próximo de zero, o setor $i$ estará distribuído regionalmente de forma semelhante ao setor $k$, ou seja, os padrões locacionais desses setores estão associados geograficamente. Caso contrário, os padrões locacionais dos setores $i$ e $k$ não estão associados geograficamente.

$C A_{i k}=\frac{\sum_{j}\left(\left|j^{e i}-j^{e k}\right|\right)}{2}$,

sendo que $0 \leq C A_{i k} \leq 1$

O cálculo do $C A_{i k}$ é indicado para identificar a orientação espacial de cadeias produtivas. Para a região Nordeste, foram calculados os $C A_{i k}$ para os grupos de setores da Tabela 3 .
Os resultados da Tabela 3 evidenciam que os setores da indústria de transformação e de serviços industriais de utilidade pública, indústria de transformação e comércio e comércio e serviços são aqueles que possuem os maiores níveis de associação geográfica, ou seja, possuem um padrão locacional semelhante. Além disso, essa associação tornou-se mais similar nos dois primeiros casos no período analisado. Esse fato pode estar relacionado às economias de aglomeração que são potencializadas quando esses setores localizam-se próximos uns dos outros, o que estimula a lucratividade deles. Os demais pares de setores analisados, apesar de pequenos avanços no período, possuem baixa associação em relação à sua distribuição espacial.

d. Coeficiente de Redistribuição do setor $i$ entre os periodos 1995 e 2007 ( $\left.C R_{i}\right)$ : seu objetivo é analisar para cada setor a existência de um padrão

Tabela 3_Região Nordeste: coeficiente de associação geográfica entre os setores i e $k\left(C A_{i k}\right)$ - 1995 e 2007

\begin{tabular}{|c|c|c|c|c|c|c|c|c|}
\hline & $\begin{array}{l}\text { Ext. Min. } \\
\text { e Ind. Transf. }\end{array}$ & $\begin{array}{l}\text { Ext. Min. } \\
\text { e Agrop. }\end{array}$ & $\begin{array}{c}\text { Ind. Transf. } \\
\text { e Agrop. }\end{array}$ & $\begin{array}{l}\text { Ind. Transf. } \\
\text { e Serv. UP }\end{array}$ & $\begin{array}{c}\text { Ind. Transf. } \\
\text { e Comer. }\end{array}$ & $\begin{array}{l}\text { Ext. Min. } \\
\text { e Serv. UP }\end{array}$ & $\begin{array}{l}\text { Agrop. } \\
\text { e Comer. }\end{array}$ & $\begin{array}{l}\text { Comer. } \\
\text { e Serv. }\end{array}$ \\
\hline 1995 & 0,649 & 0,662 & 0,433 & 0,383 & 0,306 & 0,675 & 0,586 & 0,149 \\
\hline 2007 & 0,605 & 0,707 & 0,540 & 0,355 & 0,300 & 0,625 & 0,579 & 0,209 \\
\hline $\operatorname{Var}(\%)$ & $(-7,27)$ & 6,36 & 19,81 & $(-7,89)$ & $(-2,00)$ & $(-8,00)$ & $(-1,21)$ & 28,71 \\
\hline
\end{tabular}

Fonte: Elaboração própria com base nos dados da RAIS/MTE. 
de concentração ou dispersão espacial ao longo do tempo. Em outras palavras, esse coeficiente permite avaliar se a distribuição espacial relativa do emprego em determinado setor se alterou entre o período inicial (1995) e o final (2007). O $C R_{i}$ varia entre $0 \mathrm{e}$ 1. Quando ele tende a zero, o setor tornou-se mais concentrado. Quando tende a um, o setor tornou-se mais disperso.

$$
C R_{i}=\frac{\sum_{j}\left(\left|j_{t 1}^{e i}-j_{t 0}^{e i}\right|\right)}{2}
$$

sendo que $0 \leq C R_{i} \leq 1$

Na região Nordeste, o $C R_{i}$ é muito baixo para todos os setores analisados (ver Tabela 4), o que indica a elevada concentração espacial da atividade econômica. A dinâmica espacial do emprego no Nordeste ainda é bastante limitada, o que impede a expansão de possíveis efeitos de encadeamento na região como um todo. A dinâmica econô- mica da região continua altamente concentrada em uma quantidade bastante limitada de áreas: em 2007, apenas 41 microrregiões (21,8\% do total) eram responsáveis por aproximadamente $80,4 \%$ do emprego industrial e 70,1\% do emprego agrícola. Isso representa um pequeno avanço em relação a 1995, quando essas mesmas microrregiões representavam $85,3 \%$ e $78,4 \%$ do emprego industrial e agrícola, respectivamente, mas ao mesmo tempo evidencia a fragilidade econômica e social da região.

e. Curvas de Localização on Coeficiente de Concentração: permitem visualizar e interpretar o grau de concentração espacial das atividades econômicas. São representações gráficas da distribuição dos dados e também podem ser chamadas de curvas de Loren₹: Estas curvas, convexas e de inclinação positiva, são formadas pela união de pontos bidimensionais localizados no eixo das abscissas (eixo $X$ ), que representa a proporção acumulada

Tabela 4_Região Nordeste: coeficiente de redistribuição setorial $\left(C R_{i}\right)$ - 1995 e 2007

\begin{tabular}{|c|c|c|c|c|c|c|c|c|}
\hline & Ext. Min. & Ind. Transf. & Serv. Ind. UP & Const. Civil & Comer. & Serv. & Agrop. & AP \\
\hline$C R_{i}$ & 0,385 & 0,182 & 0,171 & 0,178 & 0,123 & 0,113 & 0,337 & 0,171 \\
\hline
\end{tabular}

Fonte: Elaboração com base nos dados da RAIS/MTE. 
de pessoas ocupadas na região Nordeste, e no eixo das ordenadas (eixo Y), que representa a proporção acumulada da participação relativa das microrregiões na geração de postos de trabalho na região. A curva de Lorenzé representada por uma função $L(p)$, que mostra como a proporção da participação das microrregiões no emprego aumenta em razão da proporção do pessoal ocupado, considerando a participação relativa crescente. Quando a distribuição é perfeita, a curva de Lorenz assume a forma de uma linha de $45^{\circ}$, ou seja, essa linha indica a situação na qual não há concentração na estrutura setorial regional da economia de referência. Curvas à direita mostram setores mais concentrados territorialmente, enquanto curvas à esquerda revelam setores menos concentrados territorialmente. Formalmente:

$L(p)=\frac{1}{N \mu} \sum_{U} I\left\{y_{i} \leq \xi_{p}\right\}$,

sendo que $0 \leq p \leq 1$

onde $\mu$ é a participação relativa média das microrregiões no emprego; $I(\cdot)$ denota uma função indicador; e $\xi_{p}$ é o quantil de participação relativa das microrregiões $p$.
Vale salientar que a análise da curva de Lorenz pode ser complementada pelo Índice de Gini, já que esse é capaz de mensurar o grau de concentração espacial das atividades econômicas. ${ }^{4}$

O cálculo da curva de localização para a região Nordeste, nos anos 1995 e 2007, corrobora as informações fornecidas pelo coeficiente de redistribuição: o emprego setorial na região é altamente concentrado em uma pequena quantidade de microrregiões e essa situação não obteve melhorias significativas no período analisado. O setor com maior nível de desconcentração é o de administração pública, o que pode estar relacionado ao grande número de municípios da região altamente dependentes dos Fundos de Participação dos Municípios (FPMs) e dos empregos nas diferentes escalas de governo.

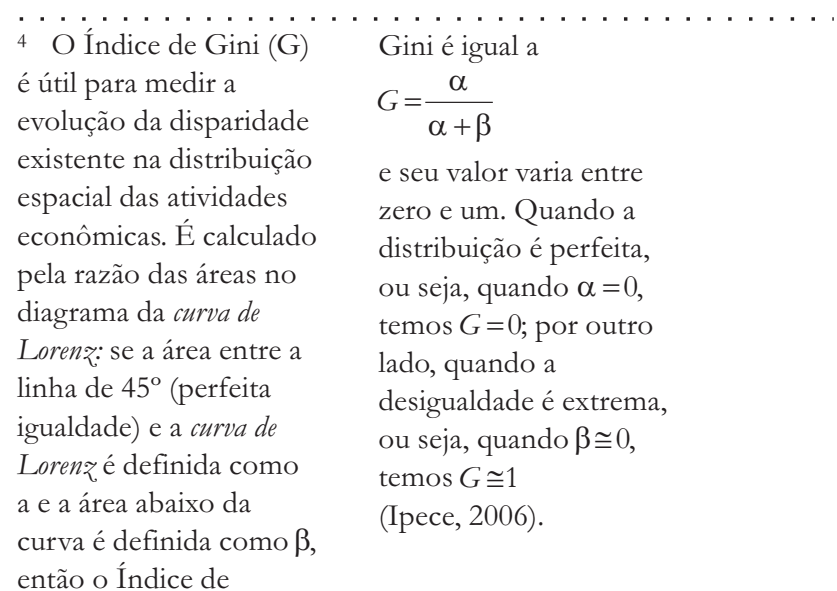


Figura 1_Curvas de localização por setor - 1995

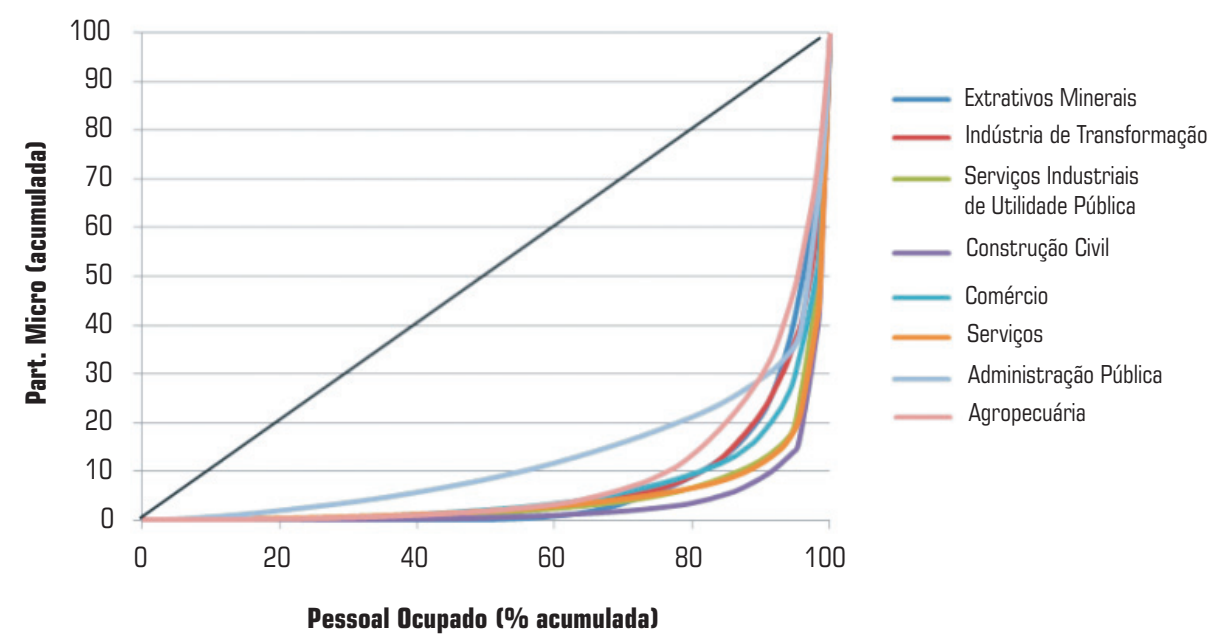

Fonte: Elaboração própria com base nos dados da RAIS/MTE.

\section{Figura 2_Curvas de localização por sertor - 2007}

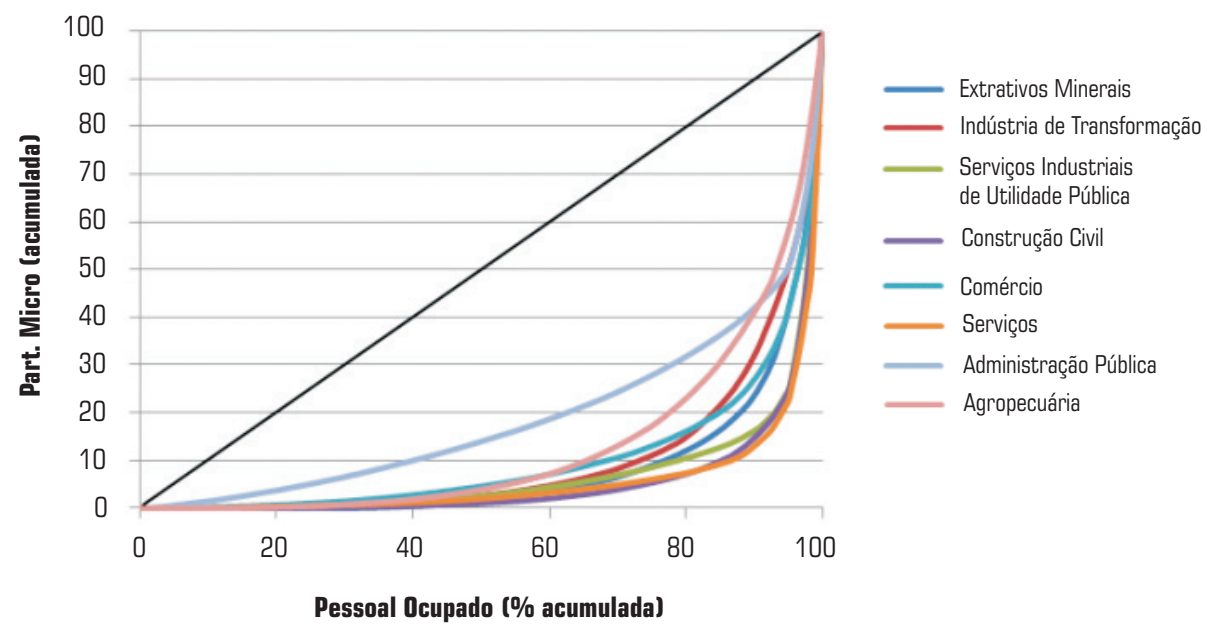

Fonte: Elaboração própria com base nos dados da RAIS/TEM. 


\subsection{2_Medidas regionais}

Indicadores utilizados para a análise da estrutura produtiva de cada região. Elas permitem identificar o grau de especialização das economias regionais em um período ou o processo de diversificação ocorrido entre dois ou mais períodos.

a. Coeficiente de Especialização da regiãoj $\left(C E_{j}\right)$ : serve para medir se a estrutura produtiva de determinada microrregião é similar à estrutura produtiva da economia de referência (região Nordeste). $\mathrm{O} \mathrm{CE}_{j}$ varia entre 0 e 1 . Quanto mais próximo de um, mais a estrutura produtiva da microrregião $j$ é diferente da economia de referência, e, provavelmente, seu nível de especialização é bastante elevado. Quanto mais próximo de zero, maior a similaridade entre a estrutura produtiva local e a estrutura produtiva regional.

$C E_{j}=\frac{\sum_{i}\left(\left|i^{e j}-i^{e o}\right|\right)}{2}$,

sendo que $0 \leq C E_{j} \leq 1$

Em 1995, apenas 14,44\% das microrregiões analisadas possuíam um $\mathrm{CE}_{j}$ entre 0,500 e 0,700. As demais (85,56\%) possuíam $\mathrm{CE}_{j}$ inferior a 0,500. Em 2007, esse percentual tornou-se ainda menos favorável: $11,76 \%$ das microrregiões possuíam $C E_{j}$ entre 0,500 e 0,700 , e $88,24 \%$ possuíam $C E_{j}$ inferior a 0,500. Esses dados evidenciam, mais uma vez, a concentração das atividades econômicas na região Nordeste: as áreas dinâmicas representam parcela relativamente pequena de seu território, são esparsas e possuem elevado nível de concentração e especialização. Tais fatores, tomados em conjunto, acabam por diminuir a potencialidade que essas áreas poderiam exercer sobre sua vizinhança (binterlands), e muitas delas tornam-se verdadeiros enclaves, cuja principal relação econômica ocorre com agentes externos à região como um todo, consolidando o papel complementar e dependente da economia nordestina no cenário nacional.

\section{b. Coeficiente de Reestruturação da regiãoj} entre dois periodos $\left(C T_{j}\right)$ : seu objetivo é avaliar o grau de mudança na especialização da região $j$ entre dois períodos (1995 e 2007). Em outras palavras, permite avaliar se a estrutura produtiva da região se alterou ao longo do tempo. Seu valor varia entre 0 e 1 . Se a região se especializou, ou seja, se não ocorreram mudanças significativas em sua estrutura produti- 
va, o coeficiente tende para zero. Se houve diversificação setorial do emprego, o coeficiente tendeu para um.

$$
C T_{j}=\frac{\sum_{i}\left(\left|i_{t 1}^{e j}-i_{t 0}^{e j}\right|\right)}{2},
$$

sendo que $0 \leq C T_{j} \leq 1$

Entre 1995 e 2007, apenas 4,28\% das microrregiões analisadas apresentaram coeficiente superior a 0,400 , com claros indícios de reestruturação setorial. São elas: $\mathrm{Gu}-$ rupi, Chapadas das Mangabeiras, Alto Médio Gurgueia, Chapadas do Extremo Sul Piauiense, Litoral Norte Alagoano, Santa Maria da Vitória, Paulo Afonso e Itapetinga.

Aproximadamente $56,7 \%$ das microrregiões possuem coeficientes entre 0,150 e 0,350, o que pode indicar o início de um processo de reestruturação setorial, todavia, não é indicado realizar conclusões precipitadas. Entre essas microrregiões, podem-se destacar: Gerais de Balsas, no Maranhão; Sobral, Pacajus, Litoral de Aracati e Baixo Jaguaribe, no Ceará; Vale do Açu e Seridó Ocidental, no Rio Grande do Norte; Catolé da Rocha, na Paraíba; Alto Capibaribe, Mata Setentrional e Mata Meridional, em Pernambuco; Barreiras e Bom Jesus da Lapa, na Bahia, muitas das quais são apontadas como áreas de dinamismo recente na região Nordeste (Lima, 2004).
As demais microrregiões (39,94\%) possuem coeficientes menores do que 0,150 , com baixos indícios de reestruturação produtiva. Entre essas, estão incluídas, de um lado, Fortaleza, Recife, Salvador, João Pessoa, Maceió e Aracaju, fato que provavelmente está ligado ao maior nível de diversificação produtiva dessas microrregiões, alcançado antes mesmo do período em análise. De outro, são observadas microrregiões estagnadas e de baixo dinamismo na região, sem indícios de alteração dessa situação, como, por exemplo, Baixada Maranhense, Médio Parnaíba Piauiense, Canindé, Agreste Potiguar, Seridó Ocidental Paraibano, Sertão do Moxotó, Traipu, Boquim e Jeremoabo.

\subsection{Análise Diferencial-Estrutural ("shift-share")}

O objetivo do método de análise diferencial-estrutural é identificar os componentes do crescimento econômico regional (no caso, de microrregiões) de acordo com sua estrutura produtiva entre dois períodos (1995 e 2007). Em outras palavras, o método analisa se o crescimento ocorreu em razão da existência de setores dinâmicos na estrutura produtiva microrregional, cujas taxas de crescimento $\left(\gamma_{i t}\right)$ são maiores do que a taxa de crescimento total da economia de referência - a região Nordeste $-\left(\gamma_{t t}\right)$, ou se essa estrutura tem 
participação crescente no total das microrregiões, independentemente de existirem setores dinâmicos. Apesar de esse método não possuir hipóteses sobre o comportamento da variável em análise o emprego -, ele é mais complexo do que as medidas de localização e de especialização, uma vez que procura incorporar aspectos das Teorias Clássicas da localização em sua análise. ${ }^{5}$

O crescimento do emprego regional entre o período inicial e o final é dividido em três componentes: regional $(\mathrm{R})$, proporcional ou estrutural $(\mathrm{P})$ e diferencial (D):

$$
\begin{aligned}
g_{j} & =R+P+D= \\
& =\sum_{i} E_{i j}^{1}-\sum_{i} E_{i j}^{0}
\end{aligned}
$$

O componente regional do emprego (R) na microrregião $j$ é igual ao acréscimo de emprego que essa teria se tivesse a taxa de crescimento do emprego total da região Nordeste, ou seja:

$\mathrm{R}=\sum_{i} E_{i j}^{0}\left(\gamma_{t t}-1\right)$

onde $\gamma_{t t}=\frac{\sum_{i} \sum_{j} E_{i j}^{1}}{\sum_{i} \sum_{j} E_{i j}^{0}}$

é igual a taxa de crescimento do emprego da economia de referência - região Nordeste.

O componente proporcional ou estrutural $(\mathrm{P})$ representa o montante de emprego que uma microrregião ganha ou per- de em função da sua composição setorial. Essa variação será positiva se a microrregião possuir mais setores dinâmicos; caso contrário, ou seja, se houver mais setores com taxa de crescimento inferior às da economia de referência, a variação será negativa. Esse componente permite identificar alguns fatores que atuam no crescimento regional, como, por exemplo, a influência de alterações na estrutura de demanda, da produtividade, da inovação tecnológica, etc., sobre a variação no desempenho das taxas de crescimento entre setores. Sua fórmula é dada por:

$P=\sum_{i} E_{i j}^{0}\left(\gamma_{i t}-\gamma_{t t}\right)$

onde $\gamma_{i t}=\frac{\sum_{j} E_{i j}^{1}}{\sum_{j} E_{i j}^{0}}$

é a taxa de crescimento do emprego no setor $i \mathrm{em}$ todas as microrregiões (taxa regional de crescimento do emprego no setor).

O componente diferencial (D) diz respeito ao montante de emprego que a microrregião $j$ ganhou ou perdeu graças à taxa de crescimento local do emprego de determinados setores $\left(\gamma_{i j}\right)$ ser diferente da taxa regional $\left(\gamma_{t t}\right)$. Se $\gamma_{i j}>\gamma_{i t}$, o setor $i \mathrm{da}$ região $j$ cresceu mais do que o mesmo setor no total das regiões, o que indica especialização local e que essa microrregião pode crescer mais rapidamente do que as demais 5 É preciso enfatizar que este método é uma identidade, e não um modelo, e que, portanto, é incapaz de explicar as tendências e as regularidades evidenciadas em seus resultados. É apenas uma forma analítica de gerar informações relevantes para pesquisas teóricas (Haddad et al., 1989). 
se for capaz de atrair número crescente de firmas em detrimento de outras regiões. Caso contrário, $\gamma_{i j}<\gamma_{i t}$, houve perda de competitividade no setor $i$ da microrregião $j$. Os principais fatores que influenciam a variação nesse componente e estimulam o crescimento regional são de natureza locacional, como a variação nos custos de transporte, os incentivos fiscais, etc.

$D=\sum_{i} E_{i j}^{* 0}\left(\gamma_{i j}-\gamma_{i t}\right)$

onde $\gamma_{i j}=\frac{E_{i j}^{1}}{E_{i j}^{0}}$

é a taxa de crescimento do emprego no setor $i$ da microrregião $j$.

Uma modificação do método, cujo objetivo é superar algumas críticas realizadas, foi elaborada por Esteban-Marquillas em 1972. Essa modificação introduz o efeito alocação na análise para avaliar os componentes do crescimento regional, a partir de um novo elemento chamado "emprego homotético" $\left(E_{i j}^{\prime}\right)$, que seria o emprego no setor se a microrregião tivesse uma estrutura de emprego igual à da economia de referência:

$$
E_{i j}^{\prime}=\sum_{i} E_{i j}\left(\frac{\sum_{j} E_{i j}}{\sum_{i} \sum_{j} E_{i j}}\right)
$$

O efeito competitivo é calculado com base no emprego homotético, e não há influência do efeito proporcional sobre ele:

$$
D^{\prime \prime}=\sum E_{i j}^{0 "}\left(\gamma_{i j}-\gamma_{i t}\right)
$$

Ao mesmo tempo, é introduzido o efeito alocação para explicar o componente do crescimento estrutural que não é captado pelo efeito competitivo:

$A=\sum_{i}\left[\left(E_{i j}^{0}-E_{i j}^{\prime}\right)\left(\gamma_{i j}-\gamma_{i t}\right)\right]$

Assim, o crescimento do emprego regional passa a ter quatro componentes:

$\sum_{i} E_{i j}^{1}-\sum_{i} E_{i j}^{0}=R+P+D^{\prime \prime}+A=$

$=\sum_{i} E_{i j}^{0}\left(\gamma_{t t}+1\right)+$

$+\sum_{i} E_{i j}^{0}\left(\gamma_{i t}-\gamma_{t t}\right)+$

$+\sum_{i} E_{i j}^{\prime 0}\left(\gamma_{i j}-\gamma_{i t}\right)+$

$+\sum_{i}\left[\left(E_{i j}^{0}-E_{i j}^{\prime 0}\right)\left(\gamma_{i j}-\gamma_{i t}\right)\right]$

Além disso, o efeito alocação mostra se a microrregião é especializada nos setores em que possui vantagens competitivas (quando é positivo) ou não. São quatro as alternativas possíveis (Tabela 5).

A análise diferencial-estrutural modificada foi calculada para as 187 microrregiões nordestinas, entre 1995 e 2007, com um nível de desagregação equivalente a 26 setores produtivos. Foi utilizada a mesma base de dados da seção anterior (emprego - RAIS/MTE). Na Tabela 6, os setores produtivos são classificados de acordo com seu ritmo de crescimento. 
Tabela 5_Caracterização das microrregióes de acordo com o efeito competitivo

\begin{tabular}{|c|c|c|c|}
\hline \multirow[b]{2}{*}{ Alternativas } & \multirow{2}{*}{$\begin{array}{c}\text { Efeito } \\
\text { Alocação }\end{array}$} & \multicolumn{2}{|c|}{ Componentes } \\
\hline & & Especialização & $\begin{array}{c}\text { Vantagem } \\
\text { Competitiva }\end{array}$ \\
\hline Desvantagem Competitiva, especializada & - & + & - \\
\hline Desvantagem Competitiva, não especializada & + & - & - \\
\hline Vantagem Competitiva, não especializada & - & - & + \\
\hline Vantagem Competitiva, especializada & + & + & + \\
\hline
\end{tabular}

Fonte: Haddad et al. (1989).

Tabela 6_Região Nordeste: classificação das taxas de crescimento setoriais - 1995/2007

\begin{tabular}{|c|c|c|c|c|c|}
\hline Setor & $\begin{array}{c}\text { Taxa de } \\
\text { Crescimento }\end{array}$ & Classificação & Setor & $\begin{array}{c}\text { Taxa de } \\
\text { Crescimento }\end{array}$ & Classificação \\
\hline Ext. Mineral & 1,739 & Dinâmico & Serv. Ind. UP & 0,946 & Tradicional \\
\hline Min. não Met. & 2,045 & Dinâmico & Const. Civil & 1,835 & Dinâmico \\
\hline Ind. Metalúrgica & 1,822 & Dinâmico & Comer. Varejo & 2,324 & Dinâmico \\
\hline Ind. Mecânica & 4,076 & Dinâmico & Comer. Atacado & 2,036 & Dinâmico \\
\hline Elétrica e Com. & 1,313 & Tradicional & Inst. Crédito & 0,974 & Tradicional \\
\hline Mat. Transportes & 3,355 & Dinâmico & Comer. e Adm. de Imóveis & 2,299 & Dinâmico \\
\hline Mad. Mob. & 1,430 & Tradicional & Serviços de Transporte e Comércio & 1,239 & Tradicional \\
\hline Papel e Gráfica & 1,470 & Tradicional & Serv. de Alojamento & 2,235 & Dinâmico \\
\hline Borr., Fumo, Couro & 1,573 & Tradicional & Serv. Médicos, Odonto. & 1,210 & Tradicional \\
\hline Ind. Química & 1,704 & Dinâmico & Ensino & 1,210 & Tradicional \\
\hline Ind. Têxtil & 1,614 & Tradicional & Administração Pública & 1,720 & Dinâmico \\
\hline Ind. Calçados & 6,874 & Dinâmico & Agricultura & 1,361 & Tradicional \\
\hline Alim. e Bebidas & 1,349 & Tradicional & Total da Indústria & 1,613 & Dinâmico \\
\hline
\end{tabular}

Fonte: Elaboração própria com base nos dos dados da RAIS/TEM. 
Dada a grande quantidade de microrregiões em análise, serão discutidos mais detalhadamente os indicadores de apenas 41, para os setores industriais e agrícolas, visto que essas eram responsáveis em conjunto por $80,4 \%$ e $70,2 \%$ do emprego nesses setores em 2007. Entre essas, estão incluídas áreas tradicionalmente mais dinâmicas na região e outras de melhor desempenho nos últimos anos. Tais informações podem ser observadas nas Tabelas B1 a B4 do Apêndice.

Para o total dos setores analisados, observa-se que as capitais e as regiões metropolitanas, exceto Fortaleza, Maceió e Aracaju, obtiveram ganhos no emprego graças à sua composição setorial (variação estrutural positiva - ver Tabela B.1). Entretanto, como essa variação foi calculada utilizando-se a distribuição regional do emprego no início do período em análise, é preciso rever esses valores por meio da variação diferencial (valores expressos na Tabela B.2). Neste caso, todas essas microrregiões, sem exceção, apresentaram variação líquida negativa no total do emprego, o que é em certa medida razoável, já que fatores desaglomerativos em razão da densidade urbana presente nessas microrregiões podem "expulsar" atividades menos lucrativas por área dessas localidades para seu entorno. Além disso, essas microrregiões, com exceção de Fortaleza, Natal e Aracaju, obtiveram efeitos competitivos negativos (ver Tabela B.3).
Na Aglomeração Urbana de São Luís, as maiores perdas de emprego e competitividade ocorreram nos setores extrativos minerais, metalúrgicos, de material de transporte e serviços industriais de utilidade pública. O componente diferencial do total da indústria foi negativo $(-4628,06)$, mas seu efeito competitivo foi positivo $(8396,87)$. Ademais, essa microrregião é especializada em alguns setores nos quais não possui vantagens competitivas (metalúrgicos e material de transporte) e não é especializada em setores nos quais possui vantagens competitivas (extrativa mineral, mecânica, elétrica, etc.) (ver Tabela B.4). Todavia, é preciso ressaltar que houve aumento significativo do emprego no setor mecânico, o que pode trazer bons resultados no futuro.

Em Teresina, as maiores perdas de emprego e competitividade ocorreram nos setores extrativos minerais, minerais não metálicos, têxteis e borracha (o componente diferencial do total da indústria foi negativo, isto é, -4911,91, mas o efeito competitivo foi positivo, ou seja, 5085,20). Uma característica dessa microrregião é a não especialização em setores com potencial vantagem competitiva, como extrativo mineral, minerais não metálicos, metalúrgicos, mecânicos, material de transporte e químicos. Ao mesmo tempo, há especialização em setores nos quais não há vanta- 
gens competitivas (madeira e mobiliário, borracha e têxteis). O setor com maior variação diferencial positiva e com maior efeito competitivo foi o de produtos alimentícios.

$\mathrm{Na}$ microrregião de Fortaleza, as maiores perdas de emprego ocorreram em setores intensivos em capital, como metalurgia, mecânica, elétrica e material de transporte, o que requer cuidados na análise, uma vez que a diminuição do emprego nesses setores não necessariamente implica perda de competitividade, dada a possibilidade de introdução de novas técnicas de produção, poupadoras de mão de obra. O setor calçadista também apresentou variação diferencial negativa, o que é explicado em parte pela dispersão dessa atividade no Estado. O componente diferencial do total da indústria foi negativo (-18212,91), bem como o efeito competitivo (-22463,74). Há especialização em setores que não possuem vantagens competitivas regionais, como os metalúrgicos, mecânicos, elétricos e de material de transporte, e há setor cuja vantagem competitiva não é aproveitada (calçados). Contudo, nessa microrregião também é possível observar a especialização em setores com vantagens competitivas regionais, o que é fundamental para a manutenção de seu dinamismo (papel e gráfica, químico, têxteis, borracha e couro). O setor têxtil obteve elevada variação diferencial e competiti- va, fato que está relacionado ao polo de confecções localizado nessa microrregião.

$\mathrm{Na}$ microrregião de Natal, houve diminuição do emprego no total dos setores analisados (-35142,51), e as maiores perdas ocorreram nos setores extrativos minerais, mecânicos e químicos. Já os setores de minerais não metálicos, metalúrgicos, elétricos, têxteis, de calçados e alimentícios tiveram variação diferencial positiva, bem como o total da indústria. A competitividade do emprego aumentou nessa microrregião como um todo $(59383,61)$ e para o total da indústria. Os setores com as maiores quedas no emprego também foram aqueles que obtiveram redução significativa na competitividade. A microrregião é especializada na produção extrativa mineral e mecânica, mas não possui vantagens competitivas nesses setores. Ao mesmo tempo, há setores nos quais existem vantagens competitivas e a microrregião não é especializada (minerais não metálicos, metalurgia, material elétrico, material de transporte, químicos, etc.). O único setor com vantagem competitiva e especialização local é o de produtos alimentícios e bebidas (ver Tabela B.4).

$\mathrm{Na}$ microrregião de João Pessoa, apenas os setores de produtos mecânicos e de madeira e mobiliário apresentaram ganhos no emprego e na competitividade. A 
variação diferencial para o total de setores analisados e para o total da indústria foi negativa, $(-61568,52)$ e $(-4837,90)$, respectivamente, e o mesmo pode ser observado em relação ao efeito competitivo. Observa-se ainda a especialização em setores com desvantagens competitivas (papel e gráfica, borracha e couro, têxteis, calçados) e a falta de especialização em setores com vantagens competitivas regionais (metalúrgicos, mecânicos, químicos, etc.).

A microrregião do Recife teve variação diferencial negativa e perda de competitividade em todos os setores industriais e no total de setores analisados. Esses dados corroboram os resultados já encontrados na literatura sobre a queda da participação dessa microrregião no emprego regional. Em relação à especialização, observa-se também um quadro não muito promissor: especialização em setores com desvantagens competitivas (metalúrgicos, mecânicos, elétricos, material de transporte, papel e gráfica, químicos e têxteis) e não especialização em setores com vantagens competitivas (alimentos e bebidas, calçados, borracha e couro, madeira e mobiliário, etc.).

A situação na microrregião de Maceió, é bastante parecida com a da RMR: apenas os setores extrativos minerais e de alimentos e bebidas obtiveram variação diferencial positiva e aumento da competitivi- dade. O único setor em que há especialização e vantagens competitivas é o de alimentos e bebidas. Os demais apresentam, em geral, vantagens competitivas não aproveitadas.

Na microrregião de Aracaju, a perda de emprego (total -3785,38 e industrial $-387,20)$ graças à composição setorial foi provocada principalmente pela perda de competitividade nos setores de minerais não metálicos, metalúrgicos, de material de transporte, têxteis e de calçados. Mas é preciso salientar que houve aumento da competitividade para o total do emprego analisado $(10573,80)$ e para o total industrial (19901,12), estimulados principalmente pelos efeitos competitivos bastantes elevados dos setores extrativos minerais, mecânicos, elétricos e de comunicações, químicos e de produtos alimentícios. Esse fato pode indicar uma mudança na estrutura produtiva local que favorecerá o desenvolvimento futuro da microrregião, dadas as possibilidades de efeitos de encadeamentos desses setores. Em termos de especialização, tal microrregião não foge a regra das demais: é especializada em setores com desvantagens competitivas (minerais não metálicos, material de transporte e têxtil) e não especializada em setores com vantagens competitivas (metalúrgicos, mecânicos, elétricos, químicos, etc.).

Na microrregião de Salvador, houve redução do emprego para o total anali- 
sado $(-115168,73)$ e para o total industrial $(-16516,18)$, o que provavelmente foi estimulado pela elevada variação diferencial negativa e pela perda de competitividade nos setores de minerais não metálicos, metalúrgicos, químicos, de papel e gráfica, têxteis, calçados e alimentos e bebidas. Assim como no caso da microrregião de Fortaleza, é preciso considerar que a redução do emprego nos setores intensivos em capital pode não implicar necessariamente perda de competitividade, e sim alterações no processo produtivo, com diminuição da mão de obra empregada. Em contrapartida, os setores mecânicos, elétricos e de material de transporte obtiveram variação diferencial e efeitos competitivos bastante positivos, provável reflexo da instalação da fábrica da Ford em 2001, nesse Estado. Essa microrregião também não aproveita as vantagens competitivas setoriais que possui, visto que sua principal especialização ocorre em setores desprovidos dessas (metalúrgicos, químicos e papel e gráfica).

Do total das 41 microrregiões responsáveis pela maior parte do emprego na região Nordeste do Brasil, 48,8\%, ou seja, 20 microrregiões $^{6}$ eram responsáveis por $52,5 \%$ do emprego agrícola e 20\% do emprego industrial em 2007. Os dados mostram que essas microrregiões, com exceção de Souza, Vitória da Conquista e Porto Se- guro, tiveram perda de emprego em função de sua composição produtiva para o total de setores analisados. No caso do setor agrícola, todas essas microrregiões tiveram variação estrutural negativa (ver Tabela B.1). Contudo, quando são avaliadas as possíveis mudanças ocorridas na estrutura do emprego no período em análise, a situação é bem mais promissora: para o total dos setores analisados, apenas as microrregiões das chamadas "Matas" pernambucanas e IlhéusItabuna tiveram perda líquida do emprego (variação diferencial negativa conforme Tabela B.2); no setor agrícola, há queda do emprego apenas em Mossoró, Souza, Vitória de Santo Antão, Mata Meridional, Mata Alagoana, São Miguel dos Campos e Ilhéus-Itabuna. Esse desempenho positivo no total do emprego local e especialmente no setor agrícola pode ser explicado pelos elevados efeitos competitivos observados na maioria dessas microrregiões, como em Vale do Açu, Petrolina e Juazeiro (áreas tradicionalmente dinâmicas na região Nordeste) e Gerais de Balsas e Barreiras (área de dinamismo recente - soja nos cerrados nordestinos), cujos valores podem ser observados na Tabela B.3. O grande diferencial do desempenho dessas microrregiões pode ser explicado justamente pelo fato das mesmas serem especializadas em um setor no qual possuem amplas vantagens

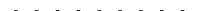

6 Gerais de Balsas, Litoral de Aracati, Baixo Jaguaribe, Mossoró, Vale do Açu, Macaíba, Souza, Petrolina, Mata Meridional Pernambucana, Vitória de Santo Antão, Mata Setentrional Pernambucana, Mata Alagoana, São Miguel dos Campos, Barreias, Juazeiro, Bom Jesus da Lapa, Santo Antônio de Jesus, Vitória da Conquista, Ilhéus-Itabuna e Porto Seguro. 
competitivas, a saber, a agricultura (das 20 microrregiões de tradição agrícola, 14 estão nessa situação - ver Tabela B.4). Em geral, o setor industrial de melhor desempenho é o de produtos alimentícios e bebidas, dada a maior facilidade de interação entre este e os setores agrícolas.

Vale destacar que, entre essas microrregiões, foram observados também os seguintes movimentos: aumento da competitividade no setor de minerais não metálicos em Gerais de Balsas; no setor de calçados, em Litoral de Aracati e Baixo Jaguaribe; nos setores metalúrgicos e mecânicos, em Mossoró, Macaíba, Mata Meridional Pernambucana, São Miguel dos Campos e Juazeiro; nos setores químicos, na Mata Setentrional Pernambucana e na Mata Alagoana; nos setores têxteis, em Barreiras; nos setores têxteis, de calçados, químicos e elétricos, em Santo Antônio de Jesus; nos setores têxteis e de calçados, em Vitória da Conquista, Ilhéus-Itabuna e Porto Seguro; e nos setores metalúrgicos, mecânicos e elétricos, em Ilhéus-Itabuna e Porto Seguro (valores expressos na Tabela B.3).

As 12 microrregiões restantes (29,3\% das mais dinâmicas) eram responsáveis em 2007 por 14,\% do emprego industrial e 6,4\% do emprego agrícola, das quais sete (Imperatriz, Sobral, Cariri, Seridó Ocidental, Campina Grande, Alto Capibaribe e Feira de Santana) obtiveram variação estrutural positiva para o total do emprego analisado, ou seja, ganharam emprego em função de sua composição setorial, e cinco (Pacajus, Catolé da Rocha, Araripina, Vale do Ipojuca e Suape) tiveram perdas, conforme dados da Tabela B.1. Para o total da indústria, a situação também foi bastante heterogênea. Quando são consideradas as possíveis mudanças na estrutura produtiva local, entre 1995 e 2007 (ver Tabela B.2), observa-se melhoria nos resultados de todas as microrregiões, que passam a ser positivos para o total do emprego e negativos em apenas duas microrregiões para o total industrial (Araripina e Imperatriz - regiões tradicionalmente dinâmicas na região Nordeste). Houve aumento da competitividade do emprego em todas essas, tanto para o total dos setores analisados quanto para o total industrial, o que pode ser observado na Tabela B.3. Deve-se destacar que, na microrregião de Imperatriz, o efeito competitivo foi bastante elevado nos setores extrativos minerais, de minerais não metálicos, metalúrgicos, mecânicos, elétricos, químicos, têxteis e de calçados; em Sobral, nos setores de papel e gráfica, químicos, alimentícios, de borracha e material de transporte; em Pacajus, no setor de calçados (resultado da dispersão dessa atividade no Ceará); em Cariri, nos setores químicos, 
têxteis e mecânicos; em Seridó Ocidental, nos setores têxteis, químicos e metalúrgicos; em Catolé da Rocha, nos setores têxteis, de calçados, minerais não metálicos e metalúrgicos; no Vale do Ipojuca e no Alto Capibaribe, nos setores têxteis; em Suape, nos setores mecânicos e de material de transporte; em Feira de Santana, nos setores elétricos e de calçados.

A análise do comportamento do emprego na região Nordeste do Brasil, entre 1995 e 2007, por meio de métodos descritivos, indica, que, nesse período, não houve mudanças significativas na estrutura produtiva regional. Ainda há muita concentração do emprego, apesar das melhorias observadas. As regiões de maior dinamismo em geral mantiveram sua posição no cenário regional. Há espaço para o surgimento de outras áreas dinâmicas, mas essas só fazem reforçar a atual situação do Nordeste: relacionam-se mais com áreas extrarregionais, com baixo efeito de encadeamento na economia local, funcionando em alguns casos como enclaves. Os "Nordestes" visualizados por Araujo (1997) parecem se reforçar, e as áreas dinâmicas que surgem não são suficientes para aumentar o nível de integração da região, que continua a ter uma indústria caracterizada por produtos intermediários voltados principalmente para o mercado externo; os seto- res agrícolas dinâmicos que surgem também possuem esta característica (fruticultura e soja para exportação - nacional ou externa). Além disso, as microrregiões aproveitam de forma bastante limitada as vantagens competitivas locais.

\section{Métodos de análise multivariada: caracterizando a centralidade das microrregiões no Nordeste brasileiro}

As atividades urbanas possuem importante papel na configuração das relações de troca no espaço e, consequentemente, sobre o desenvolvimento econômico lo$\mathrm{cal} / \mathrm{regional} /$ nacional. A análise das vantagens e desvantagens dos centros urbanos, organizados em um sistema de cidades, é importante para melhor compreender a dinâmica do emprego local e, por esse motivo, é objeto de análise nesta segunda parte do trabalho.

O objetivo é identificar os principais determinantes dos níveis de centralidade das microrregiões do Nordeste brasileiro, evidenciando a importância desses para o desenvolvimento econômico local e regional. Essa discussão será realizada por meio de uma análise de componentes principais (ACP), seguida de uma análise de clusters para as microrregiões mais dinâmicas do ponto de vista do emprego na região como um todo. 


\section{1_Centralidade e rede urbana: aspectos teóricos}

O papel desempenhado pelas aglomerações urbanas no processo de desenvolvimento econômico ganhou destaque no pós-Guerra, dado o intenso progresso de urbanização mundial, em especial nos países em desenvolvimento. Assim, para identificar a contribuição dessas para o desenvolvimento, é preciso considerar os fatores que levam as atividades a se a aglomerarem em determinadas regiões. As economias e deseconomias de aglomeração estão no cerne da discussão das teorias da localização espacial, já que a distribuição das atividades produtivas é resultado da ação de forças aglomerativas (centrípetas) e de dispersão (centrífugas). Esses conceitos foram desenvolvidos inicialmente por Lösch (1954) e Von Thünen (1966), teóricos clássicos da localização espacial. No contexto desenvolvido por esses, é possível haver concentração da produção em determinadas áreas, mesmo sob a hipótese de homogeneidade espacial, por causa da existência de retornos crescentes de escala no processo produtivo. Essa externalidade tem origem na concentração espacial dos agentes econômicos e pode estar relacionada a ganhos pecuniários (pela proximidade física de fornecedores e clientes), tecnológicos (spillovers de conheci- mento são facilitados pelo contato físico dos agentes e pela troca de informações) e a formação de mercados de trabalho amplos e especializados (região mais atrativa para trabalhadores e firmas em um círculo virtuoso) - tríade marshalliana.

O foco de análise dos teóricos urbanos é a externalidade tecnológica, uma vez que essa só ocorre mediante interações sociais entre diferentes atores e é classificada como "economias de localização" (marshallianas) e "economias de urbanização" (ou jacobianas). No primeiro caso, as firmas são beneficiadas pela concentração da indústria em determinado centro urbano, como destacado por Marshall (1982) (economias externas às firmas, mas internas à aglomeração). No segundo caso, as firmas são beneficiadas pela diversificação produtiva, pela própria escala urbana e pela oferta de serviços sofisticados à produção, como evidenciado por Jane Jacobs (economias internas à indústria e à localidade, mas externas às firmas).

Cabe aqui ressaltar alguns aspectos fundamentais das economias de urbanização. Segundo Jacobs (1969), a especialização produtiva não é fator central para o desenvolvimento urbano, visto que não proporciona condições essenciais à inovação e, desta forma, não é capaz de evitar que uma região fique estagnada mesmo quando su- 
as indústrias são altamente eficientes. Em contrapartida, nos grandes centros urbanos que contam com uma expressiva quantidade de serviços produtivos e de firmas fornecedoras de insumos, há maior divisão do trabalho, o que cria um ambiente propício à inovação e favorece o surgimento de novas atividades, inclusive exportadoras. Estas, por sua vez, incentivam o desenvolvimento do sistema de transportes, das comunicações, de atividades financeiras, etc., o que torna esses centros extremamente atraentes do ponto de vista da produção. Tais vantagens oriundas da aglomeração urbana também favorecem o consumo graças a maior diversidade de bens e serviços públicos, bem como a maior facilidade de contato social e cultural, o que atrai consumidores/trabalhadores. Assim, a diversidade implica dinamismo, maior flexibilidade e adequação às mudanças, o que torna a economia menos vulnerável.

Contudo, esse processo é limitado por fatores desaglomerativos, cujo conceito fundamental para compreensão é a renda fundiária (elaborado por Von Thünen 1966 - para atividades agrícolas). A lógica por trás desse conceito refere-se ao fato de as atividades econômicas como um todo desejarem se localizar nos espaços que fornecem o maior lucro possível, que são aqueles mais próximos de seus mercados, o que gera uma concorrência pelo espaço, dando origem à renda fundiária. Assim, quanto mais denso for o centro urbano (em termos de população e renda), maior será a renda fundiária e, por esse motivo, apenas atividades altamente rentáveis por área terão condições de se localizar no núcleo do centro urbano. Além disso, a própria aglomeração gera deseconomias, relacionadas aos custos de deslocamento e às desamenidades urbanas (poluição, criminalidade, exclusão social, aceleração da migração interna, aumento do desemprego e subemprego urbanos, etc.), que contrabalançam as economias de aglomeração, reduzindo o ritmo de expansão urbana.

Como as atividades tradicionais são favorecidas por economias de localização, elas tenderão a se localizar em regiões com significativa especialização produtiva. Já as atividades dinâmicas (de alto teor tecnológico), que são favorecidas por economias de urbanização, tenderão a se localizar em regiões mais diversificadas. Neste sentido, as atividades haverão de se instalar em diferentes localidades de acordo com sua produtividade por área, dando origem a uma rede hierarquizada de cidades, como evidenciado por Christaller (1966, p. 1).

Para Christaller, há princípios (special economic-geographical laws) que governam a distribuição e o tamanho das cidades, en- 
tendidas como lugares centrais que distribuem bens e serviços para as regiões em seu entorno (binterland). Para compreender como esses princípios funcionam, ele desenvolve dois conceitos fundamentais: i) limiar da demanda de um bem, que representa o nível mínimo de demanda por um bem ou serviço que assegura sua produção local (garante retornos crescentes); e ii) alcance de um bem ou serviço, ou seja, a maior distância que os potenciais consumidores, dispersos no território, estão dispostos a percorrer para adquiri-lo. Com base nesses dois conceitos e considerando a centralização como algo inerente às atividades humanas (centralização como um princípio de ordem), Christaller estabelece uma hierarquia entre as cidades. Quanto maiores o limiar e o alcance de um bem ou serviço, menor será o número de cidades capazes de ofertá-lo em razão dos elevados custos envolvidos em sua produção.

Desta forma, o sistema seria composto de: i) lugares centrais, capazes de ofertar bens e serviços mais sofisticados, com elevados limiar e alcance da demanda, classificados em lugares centrais de ordem superior (centros cujas funções se estendem por uma ampla região - exemplo: a economia de referência) e lugares centrais de ordem inferior (centros cujas funções estendem-se por regiões menores do que a economia de referência); e ii) regiões auxiliares/complementares aos centros de primeira ou de segunda ordem, cujos bens e serviços ofertados possuem limiar e alcance de demanda mais restritos. A aplicação desse método indica uma tendência à formação de arranjos hexagonais para a distribuição de cidades em uma determinada região. Além disso, Christaller destaca que o conceito de lugar central não necessariamente limita-se à cidade.

No caso da região Nordeste do Brasil, de acordo com estudos realizados pelo IBGE em 2007, apenas três aglomerações urbanas alcançaram níveis elevados de centralidade na rede urbana nacional: Fortaleza, Recife e Salvador (são consideradas metrópoles e obtêm nível de centralidade 1C em uma escala de 1 a 5). Há seis "capitais regionais" de nível A (São Luís, Teresina, Natal, João Pessoa, Maceió e Aracaju), quatro de nível B (Campina Grande, Feira de Santana, Ilhéus-Itabuna e Vitória da Conquista) e oito de nível C (Imperatriz, Juazeiro do Norte-Crato-Barbalha, Sobral, Mossoró, Caruaru, Petrolina-Juazeiro, Arapiraca e Barreiras), que seriam lugares centrais de segunda ordem na tipologia de Christaller. Entre os demais municípios, haveria 51 centros sub-regionais (níveis A e B) e 1.659 centros locais, considerados regiões complementares. Neste sentido, o objetivo da 
análise proposta é identificar os principais fatores determinantes da centralidade na região Nordeste. Dada a grande quantidade de municípios, a análise é realizada em termos microrregionais, e os indicadores de centralidade foram considerados iguais aqueles correspondentes aos dos municípios mais importantes.

\subsection{Metodologia e Base de Dados}

\subsection{1_ A análise multivariada: \\ análise de componentes principais e identificação de regióes homogêneas}

A análise conjunta das variáveis selecionadas permitirá identificar as principais características da centralidade das microrregiões nordestinas. Serão utilizadas duas técnicas de análise multivariada para a consecução desse objetivo.

A primeira é a análise de componentes principais (ACP), cuja finalidade é construir um conjunto de variáveis $Z_{p}, Z_{2}$, ..., $Z_{n}$ estatisticamente independentes a partir de uma transformação linear de um dado conjunto de variáveis observadas $X$, $X, \ldots, X_{n}$ que são correlacionadas. A ACP cria índices (componentes principais) que, por construção, possuem correlação igual a zero e assim mantêm a hipótese de independência das variáveis explicativas do método de regressão linear. Além disso, não é necessário realizar hipóteses a respeito da distribuição de probabilidade das variáveis originais, já que esse é um método estatístico não paramétrico. Essa técnica permite reduzir o número de variáveis consideradas na análise a um número pequeno de componentes principais e tem por objetivo identificar a menor quantidade possível de combinações lineares usadas para resumir dados, com perda mínima de informações no processo.

As combinações lineares possuem pesos $\left(a_{i j}\right)$ determinados a partir de duas condições: i) as variáveis $Z_{i}$ são ortogonais e, portanto, não correlacionadas, o que permite medir dimensão diferente nos dados e identificar a informação individual e conjunta dos componentes; e ii) as variáveis $Z_{j}$ são calculadas de forma que $\operatorname{var}\left(Z_{p}\right)>$ $\operatorname{var}\left(Z_{2}\right)>\ldots>\operatorname{var}\left(Z_{n}\right)$ para $n$ variáveis, ou seja, o primeiro componente principal $\left(Z_{1}\right)$ mostra o maior percentual da variação nos dados observados; o segundo componente $\left(Z_{2}\right)$ mostra a segunda maior variação e assim sucessivamente. As variâncias de cada componente são obtidas a partir dos autovalores da matriz de correlação (pois os dados precisam ser padronizados) - quadrada e simétrica - e os autovetores associados a esses autovalores ordenados fornecem os coeficientes para os componentes principais, sendo o primeiro associado ao maior autovalor, o segundo ao segundo maior autovalor e assim por diante. 
No problema em questão, cada microrregião $j$ será representada por uma combinação linear das variáveis $X_{i j}$, para $i=1$, $2, \ldots, 11$ - total de variáveis $-\mathrm{e} j=1,2, \ldots$, 187 - total de microrregiões em análise.

A ACP é útil para construir índices e para realizar uma classificação preliminar das microrregiões em estudo. Por esse motivo, após a aplicação desse método, optase por realizar uma análise de clusters para construir uma rede hierarquizada das microrregiões nordestinas, identificando aquelas que possuem maiores níveis de centralidade e que, portanto, são as mais importantes no cenário regional. O objetivo é agrupar pontos multivariados em classes de acordo com seu grau de homogeneidade, segundo as características de centralidade consideradas. O método escolhido para a análise de clusters foi o método aglomerativo hierárquico, o qual tem como ponto de partida uma matriz de distância euclidiana. A análise de clusters é realizada para todas as microrregiões, cujos grupamentos são destacados em um dendograma. Para melhor visualização, o dendograma aqui representado inclui apenas as microrregiões mais dinâmicas do ponto de vista do emprego regional.

\subsubsection{Base de Dados}

Os dados sobre a rede urbana nacional utilizados para a realização do trabalho são fornecidos pelo IBGE. A base de dados é a REGIC para o ano de 2007. Essa inclui uma série de informações sobre diversas pesquisas realizadas por essa e por outras instituições, como o Banco Central do Brasil e o Instituto Nacional de Estudos e Pesquisas Educacionais (INEP).

As variáveis consideradas na análise são indicadores de centralidade à medida que evidenciam a existência ou não de produtos e serviços sofisticados na localidade. Além disso, também são considerados alguns indicadores de atividade econômica:

- produto interno bruto (pib);

- percentual de diversidade dos setores de comércio (div_com) e serviços (div_serv): quanto mais elevado, maior a quantidade de produtos e serviços sofisticados ofertados na microrregião;

- número de banco existentes na microrregião (nbco): proxy para o nível de desenvolvimento e o desempenho do sistema bancário local;

- número de tipos de curso de graduação (tc_grad), total de matrículas na graduação (mgrad) e percentual de cursos de pós-graduação de excelência, ou seja, com conceito 6 ou 7 na avaliação da Capes (p_cexc): proxies para o desempe- 
nho e a qualidade do sistema educacional de nível superior local;

- centralidade de saúde (saude): indicador da qualidade e da diversificação do sistema de saúde local;

- número de sedes das maiores empresas (gemp): proxy para a atratividade local do ponto de vista do produtor;

- domínios de internet por 10.000 habitantes (dhab): variáveis indicadoras do avanço das redes de comunicação locais;

- conexão aérea (lig_exter): indicador da qualidade e da diversificação das conexões aéreas locais. Esta variável funciona como indicadora da qualidade e da agilidade das condições de acesso à localidade.

Para a análise de clusters especificamente, foi incluída uma variável indicadora do nível de centralidade local (cent), baseada no nível de centralidade calculado pelo IBGE no estudo sobre a rede urbana nacional: quanto mais elevado o valor dessa variável, maior o nível de centralidade local.

Cabe ressaltar aqui que os indicadores de centralidade para as microrregiões consideraram o maior nível entre os municípios que as compõem, e as variáveis microrregionais foram construídas com base nas informações municipais. Algumas microrregiões obedeceram a um critério diferente de aglomeração para compatibilização com a base de dados, uma vez que a obtenção dos dados sobre a rede urbana nacional pelo próprio IBGE extrapola em certas situações a área da microrregião. Isso aconteceu nos casos das aglomerações urbanas do Recife, de Aracaju, Natal, Salvador e Petrolina-Juazeiro.

\subsection{Discussão dos resultados: determinantes da centralidade na região Nordeste do Brasil}

As 187 microrregiões foram analisadas procurando agrupá-las segundo características similares em seus indicadores de centralidade. Os resultados da ACP para a amostra no ano de 2007 indicam que os dois primeiros componentes principais explicam 78,2\% da variância total das variáveis.

A análise dos componentes (Tabela 7) revela que o primeiro componente principal representa um importante indicador $\mathrm{da}$ centralidade local. Todas as variáveis analisadas contribuem de forma positiva para esse componente, e o número de matrículas na graduação, o PIB, os tipos de curso de graduação, a diversidade dos serviços e do comércio e a presença de internet contribuem de forma mais significativa, o que está de acordo com as observações levantadas pelos teóricos urbanos, visto que os principa- 
is centros urbanos tendem a se especializar em atividades terciárias, especialmente naqueles com maior nível de sofisticação. As demais variáveis têm contribuição bastante homogênea, em torno de 0,275. Esse primeiro componente evidencia e sintetiza os fatores determinantes da centralidade de uma microrregião, e, quanto mais elevado for o seu valor, maior será o nível de centralidade da localidade. Observa-se que as microrregiões de maior dinamismo local em termos de emprego também são aquelas com níveis de centralidade mais elevados (as microrregiões metropolitanas, Campina Grande, Ilhéus-Itabuna, Porto Seguro, Petrolina-Juazeiro, Barreiras, Imperatriz, Vale do Açu, Bom Jesus da Lapa, etc.).

Em relação ao segundo componente principal, observa-se que esse pode ser considerado um índice que relaciona as vantagens e desvantagens do excesso da aglomeração urbana para a centralidade local. A variável de maior importância para esse componente é o percentual de cursos de excelência. As variáveis "diversidade de comércio e serviços" e "presença de internet" contribuem de forma negativa para esse componente, ou seja, o aumento dessas variáveis contribui para a centralidade local, mas também impõe custos elevados para a localidade, pois atrai grande massa populacional que acaba agravando o congestionamento urbano. Quando a localidade não é capaz de lidar com esses custos, a própria centralidade pode ser afetada. No caso do Nordeste brasileiro, as microrregiões com maiores congestionamentos urbanos possuem valores menos expressivos desse componente (Fortaleza, Salvador e Recife).

A análise conjunta dos dois primeiros componentes principais auxilia a compreensão das características da centralidade das microrregiões, segundo o quadrante da sua localização, conforme a Figura 3 (apenas as microrregiões mais dinâmicas do ponto de vista do emprego foram plotadas no gráfico para melhor visualização). As microrregiões no primeiro e no segundo quadrantes apresentam níveis de centralidade elevada e poderiam ser caracterizadas

Tabela 7_Região Nordeste: coeficientes dos componentes principais - análise de centralidade - 2007

\begin{tabular}{|c|c|c|c|c|c|c|c|c|c|c|c|c|c|}
\hline & pib & div_com & div_serv & nbco & tc_grad & mat_grad & pcexc & saude & dhab & lig_exter & gemp & Var_exp & Var_acum \\
\hline comp1 & 0,337 & 0,301 & 0,317 & 0,254 & 0,324 & 0,349 & 0,207 & 0,299 & 0,318 & 0,276 & 0,308 & 68,7 & 68,7 \\
\hline comp2 & 0,202 & $-0,475$ & $-0,434$ & 0,234 & - & 0,146 & 0,524 & - & $-0,345$ & - & 0,258 & 9.6 & 78,2 \\
\hline comp3 & $-0,213$ & - & $-0,142$ & 0,579 & - & $-0,152$ & $-0,259$ & 0,438 & $-0,203$ & 0,381 . & $-0,349$ & 6.9. & 85,1 \\
\hline
\end{tabular}

Fonte: Elaboração própria com base em dados do IBGE/REGIC.

Obs.: (-) representa contribuição inferior a $10 \%$ da variável no componente. 
como lugares centrais de ordem superior e inferior na região (Fortaleza, Salvador, Recife, Campina Grande, Teresina, Maceió, Ilhéus-Itabuna, João Pessoa, São Luís, Natal e Aracaju). No terceiro e no quarto quadrantes, estão localizadas as microrregiões que podem ser consideradas complementares, de ordem inferior e superior, respectivamente, na região (Araripina, Petrolina-
Juazeiro, Imperatriz, Porto Seguro, Barreiras, Vale do Açu, Cariri, etc.).

Assim, a ACP corrobora os resultados encontrados na primeira parte do trabalho, visto que as microrregiões com os maiores níveis de centralidade - regiões metropolitanas (os lugares centrais) - são as mesmas que apresentaram o melhor desempenho em termos de emprego entre

\section{Figura 3_ Distribuição das microrregiões de acordo com os dois primeiros} componentes principais

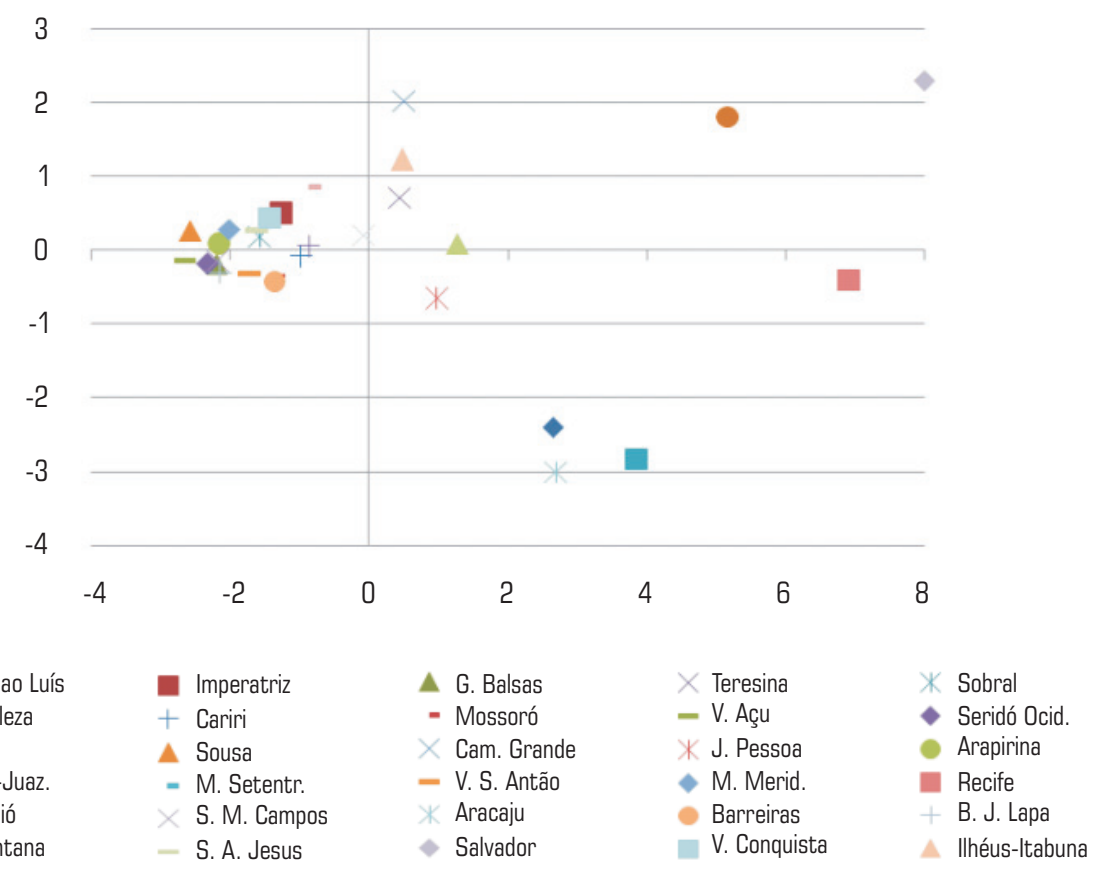

Fonte: Elaboração própria com base nos dados do IBGE/REGIC. 
1995 e 2007. Por fim, a técnica de agrupamento hierárquico complementa e ratifica os resultados encontrados. Considerando diversas variáveis indicadoras de centralidade, a análise de clusters identifica que as microrregiões mais dinâmicas e com maiores níveis de centralidade apresentam forte proximidade entre suas variáveis, criando clusters de três níveis:

i. são identificados dois clusters metropolitanos centrais de ordem superior: o primeiro formado pelas microrregiões do Recife, de Fortaleza e de Salvador, e o segundo, por Natal, Aracaju e São Luís;

ii. também são identificados dois clusters centrais de ordem inferior: um formado pelas microrregiões de Teresina, Maceió e João Pessoa (metropolitano), e o outro, pelas microrregiões de Ilhéus-Itabuna e Porto Seguro; e

iii. as demais microrregiões formam diversos clusters complementares, tanto de ordem superior quanto inferior.

As demais microrregiões em análise, que não foram plotadas na Figura 4, são agrupadas em um único cluster, dado o baixo dinamismo delas (em termos de emprego) e a ausência de centralidade. Em outras palavras, a análise de clusters ratifica a afirmação de Araújo (1997), identificando os vários "Nordestes" dentro da região Nordeste do Brasil.

\section{5_Considerações finais}

A estrutura produtiva da região Nordeste passou por uma série de transformações no período posterior à Segunda Guerra Mundial, o que estimulou consideravelmente a dinâmica econômica local. Todavia, essas mudanças não foram suficientes para alterar questões estruturais mais marcantes na região, como a grande heterogeneidade intrarregional. Em alguns casos, a tendência concentradora dos investimentos privados foi reforçada pela ação estatal, o que deu origem a alguns polos de desenvolvimento nos mais variados setores (indústria de transformação, fruticultura irrigada, etc.), bem como consolidou a posição desfavorável de áreas tradicionalmente estagnadas, como as zonas canavieiras e o semiárido.

Esses polos dinâmicos possuem estruturas produtivas bastante modernas e têm sido objeto de estudo de vários autores, dada a contribuição deles para o desempenho econômico da região como um todo. Contudo, como suas principais relações, em geral, são extrarregionais, os impactos que eles poderiam causar sobre seus binterlands acabam sendo limitados. 
Figura 4_Clusters - Agglomerative Hierarchical (distância euclidiana) - 2007

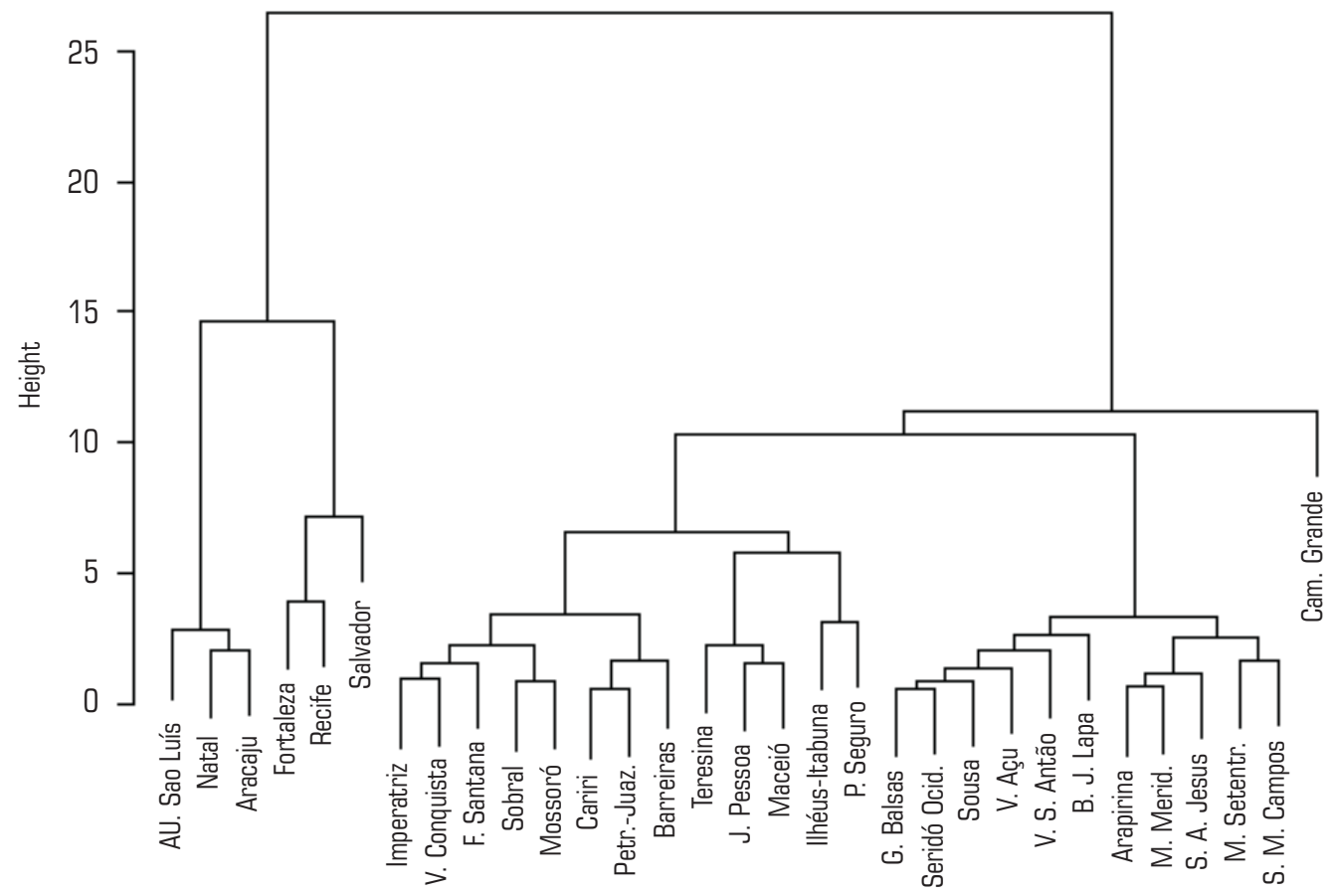

Fonte: elaboração própria com base nos dados do IBGE/REGIC.

Analisando a dinâmica do emprego nas microrregiões do Nordeste, em especial naquelas indicadas pela literatura existente como as de maior dinamismo no período pós-1980 (Araújo, 1997; Lima, 2004, etc.), observa-se alguma melhoria na distribuição dessa variável; porém, essa continua a ser bastante limitada. O cálculo das medidas de localização e de especialização indi- ca que houve desconcentração do emprego em praticamente todos os setores analisados, especialmente na indústria de transformação, o que pode contribuir para o desenvolvimento futuro da região. Todavia, essa desconcentração foi concentrada, uma vez que, em 2007, apenas 41 microrregiões (de um total de 187) eram responsáveis por $80,4 \%$ e $70,2 \%$ do emprego nos 
setores industriais e agrícolas, respectivamente, da região. Em relação à diversificação das estruturas produtivas locais, apenas $11,76 \%$ das microrregiões obtiveram resultados promissores. Um resultado positivo parece ser o esforço para a reestruturação das cadeias produtivas locais (aproximadamente $61 \%$ das microrregiões obtiveram coeficientes de reestruturação razoáveis); contudo, esse resultado precisa ser analisado com cautela. A análise diferencial-estrutural corrobora os resultados encontrados pelas medidas regionais: há alguns indícios de melhoria nas microrregiões indicadas, mas esses movimentos ocorrem muito lentamente e ainda de forma limitada no território. Em geral, as microrregiões são especializadas em setores nos quais não possuem vantagens competitivas, ao mesmo tempo em que não aproveitam as vantagens em outros setores, o que limita o seu desempenho.

Os resultados da análise multivariada indicam que os principais determinantes da centralidade local estão relacionados à diversidade dos setores de comércio e serviços (maior oferta de produtos sofisticados) e ao aumento da educação de nível superior. Esta análise indicou ainda que as microrregiões que têm conseguido avançar nesse sentido são justamente aquelas com maior dinamismo em termos de emprego (as regiões metropolitanas, as áreas tradici- onalmente dinâmicas - Petrolina/Juazeiro, Campina Grande, Imperatriz, etc. - e as áreas de maior dinamismo nos últimos anos, como Barreiras, Gerais de Balsas, Cariri). A análise de clusters identificou cinco grupos na região: os dois primeiros, formados por microrregiões que incluem as capitais e os polos dinâmicos (Ilhéus-Itabuna e Porto Seguro), podem ser considerados lugares centrais metropolitanos de ordem superior e inferior, respectivamente. Os dois grupos seguintes (englobam 20 microrregiões dinâmicas em termos de emprego) seriam clusters complementares de ordem inferior (ex. Barreiras, Gerais de Balsas, Vale do Açu, Mossoró, etc.) e superior (Petrolina-Juazeiro, Araripina, Porto Seguro, Feira de Santana, Imperatriz, etc.) no cenário regional. As demais microrregiões, com baixo dinamismo do emprego, são agrupadas em um único cluster com ausência de centralidade (seriam regiões complementares aos dois grupos complementares no contexto regional).

Em outras palavras, a análise realizada identifica alguma melhoria ocorrida em termos de emprego no período analisado, os vários "Nordestes" existentes, bem como estabelece uma hierarquia entre eles, o que pode ser útil para a elaboração e aplicação de políticas de desenvolvimento econômico para a região. 


\section{Referências bibliográficas}

ARAÚJO, T. B. de. Nordeste, Nordestes: que Nordeste? In: AFFONSO, R. B. A.; SILVA, P. L. (Orgs.). Desigualdades regionais e desenvolvimento. São Paulo: Fundap/Unesp, 1995.

ARAÚJO, T. B. de. Herança de diferenciação e futuro de fragmentação. Estudos Avançados, n. 29, USP/IEA, São Paulo, 1997.

CHRISTALLER, W. Central places in Southern Germany. Prentice-Hall New Jersey, 1966.

CROCCO et al. Metodologia de identificação de arranjos produtivos locais potenciais: uma nota técnica. Belo Horizonte: Cedeplar/UFMG, 2003. (Texto para Discussão, n. 191).

GUIMARÃES NETO, L. Introdução à formação econômica do Nordeste. Recife: Massangana, 1989.

HADDAD, P. R et al. Economia regional: teorias e métodos de análise. Fortaleza: BNB - ETENE, 1989.

HIRSCHMAN, A. O. The strategy of economic development. New Haven: Yale University Press, 1958.

INSTITUTO BRASILEIRO DE GEOGRAFIA E ESTATÍSTICA IBGE. Regiões de influência das cidades. Rio de Janeiro, 2008.
INSTITUTO DE PESQUISA E ESTRATÉGIA ECONÔMICA DO CEARÁ - IPECE. O Índice de Gini como medida de concentração de renda. Fortaleza, 2006. (Nota Técnica, n. 14). Disponível em: <http://www.ipece.ce.gov.br/ publicacoes/notas_tecnicas/ NT_14.pdf $>$. Acesso em: 04 maio 2010.

JACOBS, Jane. The economy of cities. New York: Random House, 1969.

LIMA, A. C. C; LIMA, J. P. R.

Indústrias de transformação e extrativa mineral no Nordeste: desempenho e tendências pós-1990. Recife: Pimes, 2005. (Texto para Discussão, n. 485)

LIMA, J. P. R. Economia do Nordeste: tendências recentes das áreas dinâmicas. Análise Econômica, n. 21/22, mar./set., Porto Alegre, 1994.

LIMA, J. P. R. Nordeste do Brasil: revisitando as áreas dinâmicas em meio à estagnação. In: ENCONTRO DA SOCIEDADE BRASILEIRA DE ECONOMIA POLÍTICA, 10., 2004, Campinas. Anais... Campinas, 2004.

LÖSCH, A. The economics of location. New Haven: Yale University Press, 1954.
MARSHALL, A. Principios de economia. São Paulo: Nova Cultural, 1982. (Coleção Os Economistas).

SIMÕES, R. F. Métodos de análise regional e urbana: diagnóstico aplicado ao planejamento. Belo Horizonte: Cedeplar/UFMG. 2005. (Texto para Discussão, n. 259).

VON THÜNEN, J. H. The isolated state. New York: Pergamon Press, 1966.

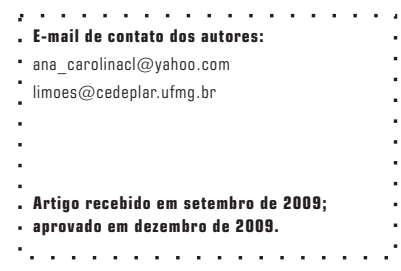


Apêndice
Tabela A.1 Região Nordeste: microrregiões com especialização produtiva em 2007

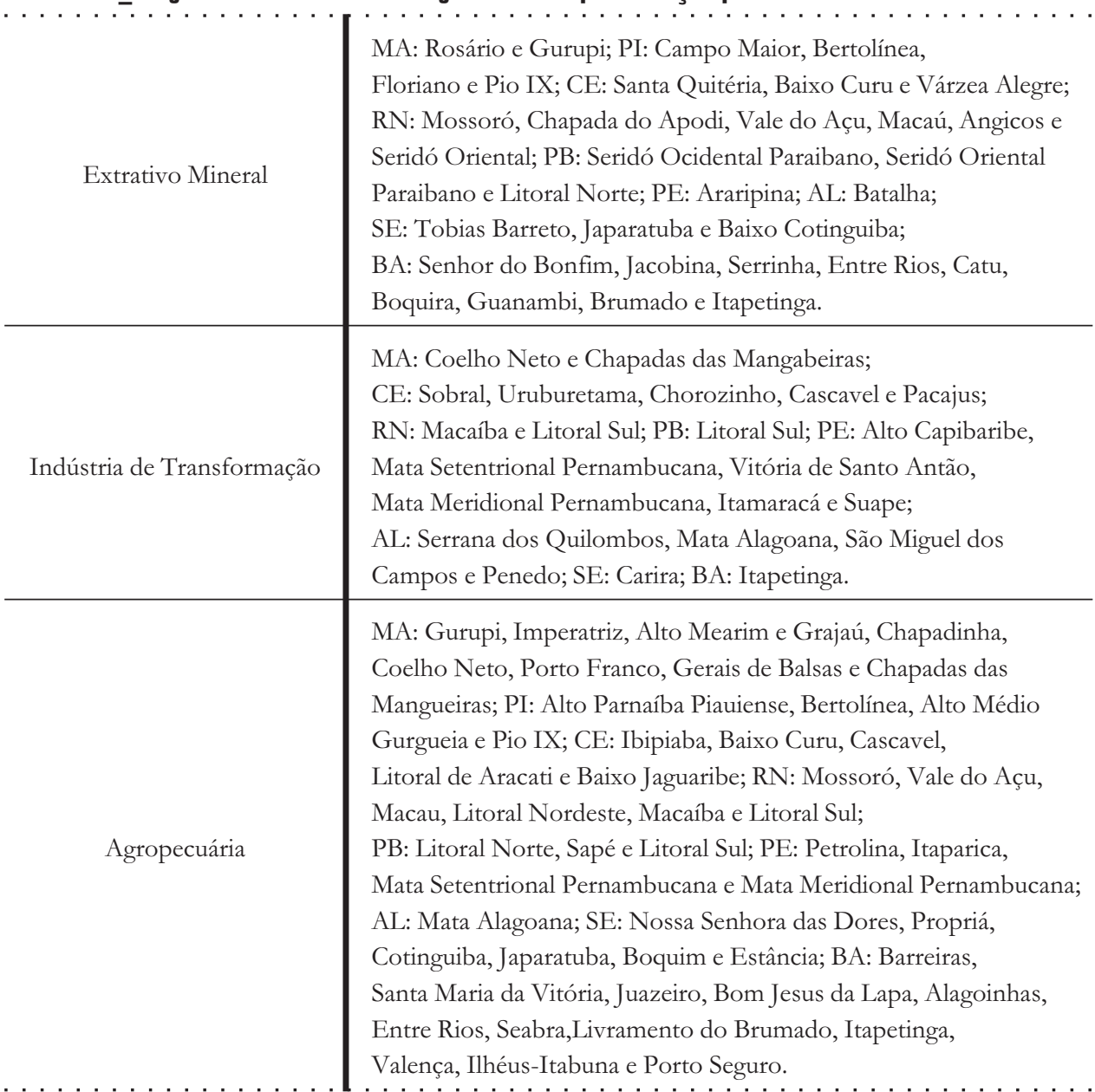


Tabela B.1_Região Nordeste: decomposição setorial da variação proporcional ou estrutural (P) - 1995/2007

(continua)

\begin{tabular}{|c|c|c|c|c|c|c|c|c|c|c|c|c|c|c|c|c|}
\hline & $\begin{array}{l}\text { Ext. } \\
\text { Min }\end{array}$ & $\begin{array}{l}\text { Não } \\
\text { met. }\end{array}$ & Met. & Mec & Ele. & Transp. & Madei. & Papel & Borr. & Quim. & Têxtil & Calç. & Alim. & Agric. & $\begin{array}{l}\text { Tot. } \\
\text { Ind. }\end{array}$ & Total \\
\hline \multicolumn{17}{|l|}{ MARANHÃO } \\
\hline AU. São Luís & 6.4 & 107.5 & 297.2 & 182.7 & -1.2 & 439.5 & -153.5 & -175.8 & -22.0 & 0.2 & -24.9 & 10.3 & -1054.6 & -1302. & -3856.0 & 805.4 \\
\hline Imperatriz & 0.0 & 105.8 & 104.4 & 2.4 & -0.4 & 107.4 & -1048. & -22.8 & -23.5 & 0.0 & -3.5 & 5.2 & -252.1 & -136.2 & -1352.8 & 572.2 \\
\hline Gerais de Balsas & 1.1 & 0.3 & 0.1 & 4.7 & -0.4 & 1.7 & -0.3 & -1.2 & -0.1 & 0.0 & -0.1 & 5.2 & -3.2 & -121.8 & -24.7 & -438.9 \\
\hline
\end{tabular}
PIAUÍ

\begin{tabular}{|c|c|c|c|c|c|c|c|c|c|c|c|c|c|c|c|c|}
\hline Teresina & 18.6 & 349.1 & 50.2 & 45.1 & -12.1 & 194.9 & -296.4 & -175.1 & -132 & 0.2 & -221.8 & 139.6 & -1099.9 & -373.7 & -3878.3 & 1594.7 \\
\hline \multicolumn{17}{|l|}{ CEARÁ } \\
\hline Sobral & 2.0 & 135.5 & 3.8 & 2.4 & -0.4 & 1.7 & -16.7 & -4.7 & -3.4 & 0.0 & -29.3 & 14715.3 & -271.3 & -42.4 & 14407.0 & 14593.8 \\
\hline Fortaleza & 39.0 & 716.4 & 602.7 & 2472.5 & -533.3 & 1049.1 & -742.8 & -830.3 & -237 & 2.1 & -1914. & 15702.8 & -9093.0 & -1657. & 663.5 & -2164.8 \\
\hline Pacajus & 0.0 & 21.2 & 4.0 & 26.1 & -0.4 & 6.6 & -0.3 & -17.2 & -3.0 & 0.0 & -137.1 & 5.2 & -180.6 & -233.1 & -277.7 & -306.4 \\
\hline Litoral de Aracati & 2.5 & 80.2 & 0.1 & 2.4 & -0.4 & 1.7 & -10.4 & -1.2 & -0.1 & 0.0 & -0.1 & 5.2 & -89.6 & -194.4 & -18.8 & -65.8 \\
\hline Baixo Jaguaribe & 10.8 & 128.7 & 0.4 & 23.7 & -0.4 & 1.7 & -1.6 & -4.2 & -0.1 & 0.0 & -12.4 & 5.2 & -84.3 & -327.2 & 5.3 & -398.6 \\
\hline Cariri & 11.7 & 85.3 & 40.6 & 54.6 & -6.2 & 1.7 & -62.1 & -20.7 & -85.1 & 0.1 & -11.2 & 2280.2 & -745.4 & -24.6 & 1459.3 & 1622.9 \\
\hline
\end{tabular}

RIO GRANDE DO NORTE

\begin{tabular}{l|r|r|r|r|r|r|r|r|r|r|r|r|r|r|r|r|r|r|r|r|r|r|}
\hline Mossoró & 76.6 & 87.0 & 6.4 & 2.4 & -0.4 & 57.8 & -22.4 & -13.0 & -0.4 & 0.2 & -11.6 & 15.5 & -1421.4 & -2681.6 & -1392.9 & -3063.4 \\
\hline Vale do Açu & 2.1 & 172.0 & 0.1 & 2.4 & -0.4 & 8.3 & -2.5 & -1.9 & -0.1 & 0.0 & -0.1 & 5.2 & -19.1 & -597.9 & 122.1 & -164.5 \\
\hline Seridó Ocidental & 0.2 & 27.3 & 0.1 & 2.4 & -0.4 & 1.7 & -0.5 & -1.6 & -3.5 & 0.0 & -4.8 & 418.8 & -51.0 & -3.4 & 316.7 & 722.3 \\
\hline Macaíba & 5.8 & 190.1 & 2.1 & 2.4 & -0.4 & 1.7 & -9.9 & -60.3 & -21.2 & 0.1 & -128.7 & 5.2 & -821.9 & -81.8 & -924.5 & -803.0 \\
\hline Natal & 47.3 & 116.4 & 18.9 & 925.4 & -0.4 & 150.3 & -175.4 & -174.2 & -49.0 & 0.3 & -382.1 & 413.6 & -974.2 & -442.5 & -3494.2 & 2820.3 \\
\hline
\end{tabular}

\section{PARAÍBA}

\begin{tabular}{|c|c|c|c|c|c|c|c|c|c|c|c|c|c|c|c|c|}
\hline Catolé da Rocha & 0.0 & 0.3 & 1.3 & 2.4 & -0.4 & 1.7 & -2.2 & -0.5 & -0.1 & 0.0 & -5.4 & 20.7 & -12.0 & -10.3 & -29.1 & -1942.4 \\
\hline Souza & 0.1 & 9.6 & 0.6 & 2.4 & -0.4 & 1.7 & -2.2 & -2.6 & -2.0 & 0.0 & -5.0 & 72.4 & -66.6 & -37.3 & -145.6 & 47.1 \\
\hline Campina Grande & 6.6 & 230.0 & 50.5 & 208.8 & -122.4 & 36.3 & -40.2 & -86.2 & -33.9 & 0.3 & -146.8 & 5103.3 & -494.3 & -99.9 & 3944.4 & 4210.9 \\
\hline João Pessoa & 3.4 & 471.3 & 49.1 & 211.2 & -30.0 & 117.3 & -104.0 & -313.0 & -126. & 0.4 & -280.8 & 13479.5 & -2846.4 & -1367. & 8102.7 & 7388.6 \\
\hline
\end{tabular}


Tabela B.1_ Região Nordeste: decomposição setorial da variação proporcional ou estrutural (P) - 1995/2007

(conclusão)

\begin{tabular}{|c|c|c|c|c|c|c|c|c|c|c|c|c|c|c|c|c|}
\hline & $\begin{array}{l}\text { Ext. } \\
\text { Min }\end{array}$ & $\begin{array}{l}\text { Nã̃o } \\
\text { met. }\end{array}$ & Met. & Mec & Ele. & Transp. & Madei. & Papel & Borr. & Quim. & Têxtil & Calç. & Alim. & Agric. & $\begin{array}{l}\text { Tot. } \\
\text { Ind. }\end{array}$ & Total \\
\hline \multicolumn{17}{|l|}{ PERNAMBUCO } \\
\hline Araripina & 19.3 & 385.7 & 1.3 & 35.6 & -0.4 & 1.7 & -1.9 & -2.1 & -1.3 & 0.0 & -2.2 & 5.2 & -22.3 & -12.7 & 347.2 & -391.7 \\
\hline Petrolina & 0.3 & 18.4 & 7.7 & 35.6 & -2.7 & 1.7 & -6.0 & -8.4 & -38.4 & 0.0 & -21.9 & 5.2 & -347.0 & -2273. & -512.3 & -1466.9 \\
\hline Vale do Ipojuca & 4.5 & 223.5 & 26.7 & 2.4 & -314.2 & 77.6 & -44.6 & -65.2 & -26.3 & 0.3 & -78.4 & 398.1 & -620.8 & -477.4 & -866.7 & -587.5 \\
\hline Alto Capibaribe & 0.8 & 41.6 & 0.5 & 2.4 & -0.4 & 5.0 & -4.9 & -3.3 & -0.1 & 0.0 & -14.7 & 46.5 & -29.0 & -31.8 & -2.6 & 182.9 \\
\hline Mata Setentrional & 1.7 & 378.8 & 9.2 & 211.2 & -0.4 & 44.6 & -17.0 & -87.8 & -24.5 & 0.0 & -37.1 & 1902.7 & -8344.4 & -3461 & -6265.7 & -10597. \\
\hline $\begin{array}{l}\text { Vitória de Santo } \\
\text { Antão }\end{array}$ & 1.8 & 192.1 & 1.3 & 28.5 & -0.4 & 1.7 & -18.9 & -1.2 & -2.1 & 0.0 & -0.4 & 5.2 & -550.6 & -864.5 & -461.9 & -1448.1 \\
\hline Mata Meridional & 1.4 & 34.5 & 0.4 & 2.4 & -53.8 & 9.9 & -23.5 & -5.8 & -2.5 & 0.0 & -55.1 & 5.2 & -10366. & -4042 & -10619 & -15152. \\
\hline Recife & 18.0 & 1315.7 & 501.1 & 3181.9 & -1714. & 1688.4 & -579.1 & -1140. & -239 & 2.7 & -832.3 & 3950.3 & -7080.9 & -4914 & -9900.4 & 28792.0 \\
\hline Suape & 2.9 & 21.2 & 30.3 & 2.4 & -138.4 & 3.3 & -34.8 & -33.1 & -5.5 & 0.4 & -48.3 & 5.2 & -2045.7 & -2114 & -2431.7 & -4357.4 \\
\hline
\end{tabular}

ALAGOAS

\begin{tabular}{l|r|r|r|r|r|r|r|r|r|r|r|r|r|r|r|r}
\hline Mata Alagoana & 4.5 & 11.9 & 7.9 & 2.4 & -0.4 & 1.7 & -1.4 & -0.5 & -2.7 & 0.0 & -0.1 & 5.2 & -3815.6 & -1326. & -3808.2 & -5706.8 \\
\hline Maceí & 2.7 & 128.3 & 50.6 & 450.8 & -18.3 & 315.5 & -106.7 & -191.7 & -29.1 & 0.7 & -40.1 & 82.7 & -5040.5 & -545.8 & -6753.1 & -1975.8 \\
\hline S. Miguel Campos & 1.8 & 67.6 & 1.2 & 2.4 & -0.4 & 1.7 & -2.7 & -0.2 & -0.1 & 0.0 & -22.0 & 5.2 & -7050.8 & -2161. & -7031.4 & -9249.6 \\
\hline
\end{tabular}

SERGIPE

\begin{tabular}{|c|c|c|c|c|c|c|c|c|c|c|c|c|c|c|c|c|}
\hline Aracaju & 7.8 & 390.1 & 44.5 & 66.4 & -6.6 & 665.8 & -128.1 & -142.5 & -24.4 & 0.1 & -252.0 & 186.1 & -925.7 & -733.0 & -2487.2 & -6468.6 \\
\hline \multicolumn{17}{|l|}{ BAHIA } \\
\hline Barreiras & 0.7 & 9.6 & 6.4 & 2.4 & -0.4 & 36.3 & -10.1 & -1.4 & -5.9 & 0.0 & -0.5 & 5.2 & -196.9 & -428.8 & -178.1 & -130.3 \\
\hline Juazeiro & 6.2 & 23.5 & 0.4 & 2.4 & -0.4 & 46.3 & -5.7 & -12.8 & -43.9 & 0.0 & -9.7 & 41.4 & -1252.9 & -1522. & -1685.3 & -1638.9 \\
\hline Bom Jesus da Lapa & 0.0 & 3.1 & 0.1 & 2.4 & -0.4 & 1.7 & -0.8 & -3.0 & -0.1 & 0.2 & -0.1 & 5.2 & -3.9 & -54.8 & -39.7 & -45.6 \\
\hline Feira de Santana & 1.2 & 182.9 & 78.5 & 161.4 & -1.6 & 209.8 & -153.5 & -181.0 & -146.0 & 0.3 & -53.2 & 268.9 & -851.3 & -463.0 & -632.6 & 3222.1 \\
\hline Santo Ant. de Jesus & 3.1 & 54.3 & 19.3 & 118.6 & -0.4 & 14.9 & -84.3 & -120.9 & -159 & 0.0 & -4.1 & 5.2 & -880.7 & -665.3 & -1049.0 & -519.3 \\
\hline Salvador & 31.8 & 795.5 & 558.2 & 1630.1 & -297.8 & 439.5 & -435.7 & -900.2 & -123 & 6.4 & -465.3 & 718.7 & -4923.3 & -1193. & -13976. & 28347.8 \\
\hline $\begin{array}{l}\text { Vitória da } \\
\text { Conquista }\end{array}$ & 2.7 & 62.1 & 25.0 & 140.0 & -0.4 & 47.9 & -13.4 & -24.7 & -9.8 & 0.1 & -1.8 & 41.4 & -172.8 & -796.3 & 95.5 & 545.1 \\
\hline Ilhéus-Itabuna & 27.3 & 103.1 & 6.2 & 218.3 & -3.9 & 1.7 & -139.0 & -38.9 & -48.6 & 0.1 & -12.0 & 5.2 & -878.9 & -5271 & -1020.8 & -4335.2 \\
\hline Porto Seguro & 4.3 & 79.2 & 4.1 & 137.6 & -0.4 & 41.3 & -263.6 & -243.6 & -8.2 & 0.0 & -1.6 & 15.5 & -324.0 & -2174. & -560.1 & 1369.4 \\
\hline
\end{tabular}

Fonte: Elaboração própria com base nos dados da RAIS/MTE. 
Tabela B.2 - Região Nordeste: decomposição setorial da variação diferencial (D) - 1995/2007

(continua)

\begin{tabular}{|c|c|c|c|c|c|c|c|c|c|c|c|c|c|c|c|c|}
\hline & $\begin{array}{l}\text { Ext. } \\
\text { Min }\end{array}$ & $\begin{array}{l}\text { Não } \\
\text { met. }\end{array}$ & Met. & Mec & Ele. & Transp. & Madei. & Papel & Borr. & Quim. & Têxtil & Calç. & Alim. & Agric. & $\begin{array}{l}\text { Tot. } \\
\text { Ind. }\end{array}$ & Total \\
\hline \multicolumn{17}{|l|}{ MARANHÃO } \\
\hline AU. São Luís & -184. & 61.9 & -1028.7 & 1548.1 & 107.1 & -768.5 & -20.0 & 17.8 & -56.8 & -170.9 & -68.5 & -13.7 & -404 & -4152 & -4628. & -36647. \\
\hline Imperatriz & 50.3 & 271.2 & 171.5 & 198.9 & 24.7 & -130.1 & -4170.1 & 109.9 & 237.9 & 104.4 & 209.1 & 7.1 & 444.4 & 4916.3 & -3124 & 16994.6 \\
\hline Gerais de Balsas & 52.8 & 135.0 & 63.2 & -7.2 & 3.7 & 13.6 & 6.6 & 29.6 & 11.4 & 9.6 & 23.4 & -6.9 & 96.9 & 1764.4 & 450.3 & 10351.9 \\
\hline
\end{tabular}

PIAUÍ

\begin{tabular}{l|l|l|l|l|l|l|l|l|l|l|l|l|l|l|l|l}
\hline Teresina & -790. & -365.6 & 39.6 & 189.6 & 49.3 & 474.1 & -428.3 & -350. & -976. & 681.6 & -2641.6 & -95.6 & 2146. & -457.3 & -4911. & -49894. \\
\hline CEARÁ
\end{tabular}

CEARÁ

\begin{tabular}{l|r|r|r|r|r|r|r|r|r|r|r|r|r|r|r|r|}
\hline Sobral & 34.2 & -120.7 & 12.7 & -1.1 & -1.3 & 17.6 & 82.8 & 230.6 & 151.1 & 106.5 & -385.6 & -2301. & 402.5 & -38.8 & 13261 & 2212.0 \\
\hline Fortaleza & -662. & -615.6 & -419.9 & -1311.3 & -318. & -244.7 & -280.0 & 192.9 & 110.0 & 55.0 & 1297.0 & -15136 & -6617. & -1238. & -18212 & -78534. \\
\hline Pacajus & 37.3 & -82.8 & -39.9 & -12.8 & -0.3 & 448.6 & 25.6 & 174.2 & 12.8 & -79.0 & -936.8 & 8988. & 351.9 & -116.9 & 8882. & 10552.0 \\
\hline Litoral de Aracati & -85.2 & -381.5 & 0.2 & -0.1 & -1.3 & -3.4 & -41.3 & 4.6 & 8.4 & 63.3 & 12.4 & 844.1 & 478.6 & 1986.9 & 1011. & 2235.0 \\
\hline Baixo Jaguaribe & -476.7 & 955.2 & 35.5 & 9.2 & -1.3 & 102.6 & 270.4 & -10.5 & 7.4 & 8.6 & 366.4 & 3729. & 681.9 & 5903.8 & 5852. & 14445.1 \\
\hline Cariri & -185.9 & 478.8 & 244.2 & 753.2 & -21.0 & 9.6 & -155.5 & 174.1 & 797.8 & 816.4 & 385.6 & 3330. & -1545. & 198.0 & 7186. & 11285.5 \\
\hline
\end{tabular}

RIO GRANDE DO NORTE

\begin{tabular}{l|r|r|r|r|r|r|r|r|r|r|r|r|r|r|r|r|r|r|}
\hline Mossoró & 917.1 & -37.4 & 748.6 & 674.9 & 21.7 & -35.4 & 245.8 & 295.7 & 78.3 & 81.8 & -39.3 & -12.6 & -2399. & -4572.6 & -171.7 & 3727.6 \\
\hline Vale do Açu & 301.4 & -73.5 & 2.2 & 150.9 & -1.3 & -3.8 & -0.9 & 0.2 & 25.4 & -12.1 & 60.4 & -6.9 & 269.1 & 2241.1 & 963.3 & 6605.0 \\
\hline Seridó Ocidental & -4.7 & -44.6 & 45.2 & -3.1 & 3.7 & -3.4 & 7.1 & 15.7 & -31.5 & 86.3 & 1689.6 & -474.8 & 47.7 & 97.4 & 1706. & 2771.6 \\
\hline Macaíba & -120.1 & -361.8 & 22.2 & 149.9 & 17.7 & 46.6 & 144.5 & -277.8 & -163.4 & 372.8 & 2179.8 & -6.9 & -188.5 & 2502.7 & 1489. & 9765.6 \\
\hline Natal & -1216. & 70.8 & 373.5 & -1229.7 & 114.7 & -204.3 & 17.6 & 299.1 & -171.4 & -479.1 & 7373.4 & 337.1 & 1464. & -305.9 & 6199. & -35142.5 \\
\hline
\end{tabular}

PARAÍBA

\begin{tabular}{|c|c|c|c|c|c|c|c|c|c|c|c|c|c|c|c|c|}
\hline Catolé da Rocha & 1.3 & 20.0 & 211.0 & -4.1 & -1.3 & -3.4 & -7.4 & 13.1 & -1.6 & 18.1 & 232.2 & 211.5 & 65.1 & -37.8 & 784.4 & 1767.4 \\
\hline Souza & -4.0 & 4.8 & 56.9 & -4.1 & -1.3 & -3.4 & -2.4 & 7.8 & 18.4 & 76.9 & -54.9 & 50.8 & 227.3 & -50.4 & 243.9 & 1765.5 \\
\hline Campina Grande & -23.9 & -581.1 & -25.8 & -133.7 & -148.4 & -36.8 & 325.8 & 396.9 & 174.0 & 440.5 & -1043.8 & 576.5 & 40.5 & 183.6 & 4706. & 815.9 \\
\hline João Pessoa & -111.6 & -479.6 & -234.0 & 186.2 & -59.1 & -205.2 & 339.7 & -10.3 & -781.5 & -114.2 & -287.1 & -14538 & -1085 . & -516.0 & -4837 & -61568.5 \\
\hline
\end{tabular}


Tabela B.2_Região Nordeste: decomposição setorial da variação diferencial (D) - 1995/2007

(conclusão)

\begin{tabular}{|c|c|c|c|c|c|c|c|c|c|c|c|c|c|c|c|c|}
\hline & $\begin{array}{l}\text { Ext. } \\
\text { Min }\end{array}$ & $\begin{array}{l}\text { Não } \\
\text { met. }\end{array}$ & Met. & Mec & Ele. & Transp. & Madei. & Papel & Borr. & Quim. & Têxtil & Calç. & Alim. & Agric. & $\begin{array}{l}\text { Tot. } \\
\text { Ind. }\end{array}$ & Total \\
\hline \multicolumn{17}{|l|}{ PERNAMBUCO } \\
\hline Araripina & 486.0 & -352.4 & 19.0 & -49.1 & 1.7 & -3.4 & 2.0 & -7.2 & 0.3 & 3.3 & 264.9 & 17.1 & -25.0 & -11.4 & -88.0 & 4643.0 \\
\hline Petrolina & 35.4 & 159.6 & 73.6 & -3.1 & -1.2 & 10.6 & 77.5 & 111.1 & 5.0 & -15.7 & -277.7 & -5.9 & -26.2 & 4100.8 & -277.7 & 8793.4 \\
\hline Vale do Ipojuca & -156.8 & 268.8 & 89.3 & 43.9 & -10.7 & -17.7 & 435.0 & 7.3 & 234.3 & -225.8 & 4966.5 & -438.3 & 1597. & 714.3 & 6150. & 28005.7 \\
\hline Alto Capibaribe & 23.0 & 5.6 & 7.7 & -4.1 & -1.3 & 4.9 & -14.7 & -6.6 & 10.4 & 67.3 & 4880.7 & -61.9 & 154.4 & -34.6 & 5062.5 & 10250.3 \\
\hline Mata Setentrional & -15.7 & -22.5 & 51.9 & -284.8 & -1.3 & 30.4 & -6.6 & -37.4 & -127.7 & 176.6 & -727.8 & -1341. & -16451 & 1465.0 & -22851 & -18480.7 \\
\hline $\begin{array}{l}\text { Vitória de Santo } \\
\text { Antão }\end{array}$ & 10.6 & -417.1 & 54.0 & -38.9 & -1.3 & -3.4 & -30.6 & 15.6 & -7.2 & 105.4 & 173.5 & -5.9 & 3227.0 & -2490.2 & 2716.1 & 3896.5 \\
\hline Mata Meridional & -31.8 & 10.5 & 1136.5 & 72.9 & -110.3 & -1.1 & 25.1 & 4.2 & 0.1 & 30.1 & -1266.1 & -6.9 & -8881 & -8167.4 & -16796 & -14418.4 \\
\hline Recife & -24.7 & -4584.0 & -2302.1 & -3038.1 & -2297 & -2676.2 & -268.1 & -1439. & -812.3 & -2909.4 & -14997.2 & -4896. & -3300 & -13715 & -45440 & -220796. \\
\hline Suape & -35.6 & 1443.2 & 157.7 & 106.9 & -459.3 & 43.3 & -24.6 & 347.2 & -64.1 & 400.7 & -687.2 & 13.1 & 3069. & -7170.6 & 2577 & 14611.5 \\
\hline
\end{tabular}

ALAGOAS

\begin{tabular}{l|r|r|r|r|r|r|r|r|r|r|r|r|r|r|r|r|r|r|}
\hline Mata Alagoana & -158.3 & 321.4 & -86.0 & 2.9 & -1.3 & -3.4 & 5.9 & 1.1 & -26.0 & 3323.7 & -1.6 & -6.9 & 4395. & -2314.3 & 5051. & 8513.2 \\
\hline Maceí́ & 395.1 & -470.8 & -207.6 & -216.5 & -36.7 & -510.9 & -74.6 & -324.2 & -162.8 & -462.3 & -8.5 & -70.0 & 555.3 & 212.0 & -5575. & -50264.5 \\
\hline $\begin{array}{l}\text { São Miguel dos } \\
\text { Campos }\end{array}$ & 66.3 & -275.8 & 109.8 & 240.9 & 24.7 & -3.4 & -10.3 & 1.5 & -1.6 & -3.1 & -555.0 & -6.9 & 6510. & -6134.4 & 1008. & 2587.2 \\
\hline
\end{tabular}

SERGIPE

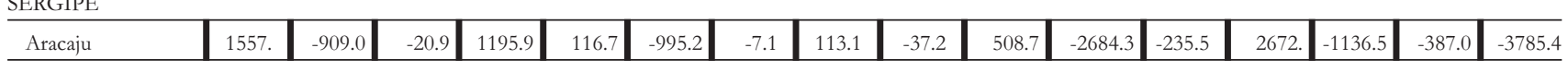
BAHIA

\begin{tabular}{|c|c|c|c|c|c|c|c|c|c|c|c|c|c|c|c|c|}
\hline Barreiras & 8.0 & 136.8 & 99.6 & 36.9 & -1.3 & -41.8 & 17.1 & 75.2 & 17.2 & 218.1 & 198.9 & -6.9 & 767.8 & 9177.5 & 1541. & 22321.8 \\
\hline Juazeiro & -176.3 & -110.1 & 30.5 & 25.9 & 5.7 & -61.0 & -8.0 & 6.1 & 8.9 & 37.7 & -149.0 & -52.0 & -2264 & 3093.4 & -3669. & 5662.2 \\
\hline Bom Jesus da Lapa & 23.3 & 64.6 & 1.2 & -4.1 & -1.3 & -1.4 & -0.3 & -8.1 & 16.4 & -650.9 & 17.4 & -6.9 & 25.2 & 488.2 & -433.4 & 4649.8 \\
\hline Feira de Santana & 78.1 & -179.9 & 206.5 & 319.8 & 1583. & -266.1 & -281.0 & 164.5 & -621.8 & 545.5 & 1736.2 & 4686. & 1629. & 1525.4 & 10310 & 21095.3 \\
\hline Santo Ant. de Jesus & 12.3 & 39.9 & 57.1 & -157.8 & 39.7 & -14.2 & 161.7 & -116.2 & -674.9 & 454.1 & 275.7 & 2246. & -1909. & 334.0 & 48.5 & 5967.7 \\
\hline Salvador & 2343. & -543.0 & -1045.2 & 2882.7 & 1018. & 6493.5 & 924.0 & -1267. & 1546. & -7941.9 & -4717.4 & -897.5 & -4834 & -2751.8 & -16516 & -115168. \\
\hline Ilhéus-Itabuna & -1101. & 9.5 & 146.3 & 1171.0 & 294.9 & 6.6 & -437.3 & -15.6 & 334.3 & -249.3 & 3208.3 & 661.1 & -285.7 & -9096.1 & 3464. & -1124.6 \\
\hline Porto Seguro & -58.4 & 464.6 & 277.2 & 469.6 & 17.7 & -3.9 & -404.7 & 313.9 & 92.9 & 199.6 & 286.0 & 273.4 & 1167. & 4413.5 & 2960. & 35821.1 \\
\hline
\end{tabular}

Fonte: Elaboração própria com base nos dados da RAIS/MTE. 
Tabela B.3_Região Nordeste: decomposição setorial do efeito competitivo (D’) - 1995/2007

(continua)

\begin{tabular}{|c|c|c|c|c|c|c|c|c|c|c|c|c|c|c|c|c|}
\hline & $\begin{array}{l}\text { Ext. } \\
\text { Min }\end{array}$ & $\begin{array}{l}\text { Nãó } \\
\text { met. }\end{array}$ & Met. & Mec & Ele. & Transp. & Madei. & Papel & Borr. & Quim. & Têxtil & Calç. & Alim. & Agric. & $\begin{array}{l}\text { Tot. } \\
\text { Ind. }\end{array}$ & Total \\
\hline \multicolumn{17}{|l|}{ MARANHÃO } \\
\hline AU. São Luís & -896.2 & 248.8 & -432.9 & 4884.7 & 13089.6 & -557.0 & -30.2 & 24.1 & -225.6 & -537.3 & -685.7 & -4324 & -1471. & -7918.3 & 8396.9 & -18515.1 \\
\hline Imperatriz & 5794. & 144.3 & 26.8 & 6300. & 1180. & -50.3 & -120.3 & 149.0 & 115.6 & 564.8 & 1950.1 & 584.4 & 882.6 & 11687.0 & 17617.4 & 54679.0 \\
\hline Gerais de Balsas & 18.5 & 2022. & 791.7 & -10.3 & 16.0 & 31.2 & 66.0 & 71.6 & 90.8 & 99.0 & 1108.9 & -51.2 & 1383. & 426.2 & 5668.0 & 18470.3 \\
\hline
\end{tabular}

PIAUÍ

\begin{tabular}{|c|c|c|c|c|c|c|c|c|c|c|c|c|c|c|c|c|}
\hline Teresina & -1172. & -400.6 & 87.6 & 2147. & 516.6 & 686.2 & -296.8 & -421.0 & -570.8 & 2768. & -2627.8 & -1973. & 664.1 & -2692.7 & 5085.2 & -12113.0 \\
\hline \multicolumn{17}{|l|}{ CEARÁ } \\
\hline Sobral & 53.3 & -39.3 & 42.9 & -26.7 & -49.3 & 347.8 & 117.6 & 1201. & 398.6 & 592.6 & -334.6 & -52.0 & 58.8 & -232.0 & 3187.4 & 8153.9 \\
\hline Fortaleza & -1417. & -992.3 & -233.0 & -817.7 & -228.6 & -198.7 & -233.8 & 147.5 & 108.3 & 49.9 & 451.2 & -8384. & -7476. & -4965.0 & -22463. & 6068.2 \\
\hline Pacajus & 1288. & -66.0 & -48.6 & -11.1 & -4.5 & 845.3 & 847.0 & 93.8 & 14.6 & -45.6 & -66.5 & 221060 & 292.7 & -48.7 & 224083. & 235953.4 \\
\hline Litoral de Aracati & -31.5 & -61.7 & 5.7 & -0.6 & -14.5 & -19.4 & -27.7 & 28.5 & 170.0 & 3315. & 1488.7 & 15964.6 & 617.0 & 763.3 & 22024.0 & 24933.3 \\
\hline Baixo Jaguaribe & -95.1 & 221.9 & 867.1 & 15.5 & -33.3 & 1369.8 & 2643.1 & -41.0 & 344.9 & 518.1 & 510.6 & 162371. & 2151. & 3102.4 & 170994. & 178390.7 \\
\hline Cariri & -73.2 & 359.3 & 111.7 & 1180. & -71.4 & 275.8 & -86.1 & 295.6 & 121.5 & 1474. & 1272.8 & 704.6 & -1180. & 2959.9 & 5222.5 & 17887.2 \\
\hline
\end{tabular}

RIO GRANDE DO NORTE

\begin{tabular}{l|r|r|r|r|r|r|r|r|r|r|r|r|r|r|r|r|}
\hline Mossoró & 71.3 & -35.4 & 2802. & 31342 & 1520. & -37.3 & 485.4 & 1028. & 3345. & 69.7 & -161.6 & -505.9 & -1239. & -809.5 & 38696.3 & 50444.1 \\
\hline Vale do Açu & 174.8 & -7.1 & 89.1 & 1418 & -18.6 & -5.6 & -3.2 & 1.2 & 659.9 & -63.0 & 9355.8 & -167.3 & 2091. & 360.2 & 13663.2 & 31105.6 \\
\hline Seridó Ocid. & -20.6 & -17.5 & 1187. & -18.6 & 33.6 & -16.1 & 75.2 & 56.8 & -19.4 & 3736. & 2185.2 & -91.6 & 89.3 & 1756.8 & 7188.1 & 11337.0 \\
\hline Macaíba & -48.3 & -61.2 & 97.3 & 2714. & 483.5 & 670.2 & 253.5 & -81.5 & -50.1 & 369.5 & 314.4 & -322.2 & -65.7 & 5663.8 & 4411.8 & 19194.8 \\
\hline Natal & -912.2 & 298.9 & 2809. & -871.8 & 47873 & -492.7 & 26.5 & 463.7 & -348.1 & -1366. & 5470.2 & 3016.6 & 6571. & -1954.2 & 63564.9 & 59383.6 \\
\hline
\end{tabular}

PARAÍBA

\begin{tabular}{l|r|r|r|r|r|r|r|r|r|r|r|r|r|r|r|r}
\hline Catolé da Rocha & 26.0 & 588.0 & 472.5 & -23.1 & -11.2 & -15.1 & -18.3 & 155.0 & -24.6 & 104.8 & 249.1 & 774.8 & 484.0 & -213.2 & 2826.5 & 4305.9 \\
\hline Souza & -29.9 & 7.3 & 411.3 & -33.8 & -16.5 & -22.1 & -8.8 & 24.8 & 28.1 & 41.2 & -92.9 & 78.0 & 448.4 & -114.6 & 811.7 & 1597.4 \\
\hline Campina Grande & -26.2 & -254.2 & -14.9 & -86.0 & -40.4 & -75.2 & 437.7 & 254.8 & 104.7 & 278.2 & -412.8 & 85.6 & 73.4 & 1063.4 & 321.3 & 3750.3 \\
\hline João Pessoa & -1141. & -492.7 & -668.7 & 570.1 & -315.9 & -625.0 & 849.5 & -8.7 & -604.3 & -226.5 & -285.6 & -3934.4 & -1642. & -1051.1 & -6160.0 & -43047.5 \\
\hline
\end{tabular}


Tabela B.3_Região Nordeste: decomposição setorial do efeito competitivo (D’) - 1995/2007

(conclusão)

\begin{tabular}{|c|c|c|c|c|c|c|c|c|c|c|c|c|c|c|c|c|}
\hline & $\begin{array}{l}\text { Ext. } \\
\text { Min }\end{array}$ & $\begin{array}{l}\text { Não } \\
\text { met. }\end{array}$ & Met. & Mec & Ele. & Transp. & Madei. & Papel & Borr. & Quim. & Têxtil & Calç. & Alim. & Agric. & $\begin{array}{l}\text { Tot. } \\
\text { Ind. }\end{array}$ & Total \\
\hline \multicolumn{17}{|l|}{ PERNAMBUCO } \\
\hline Araripina & -32.7 & -16.4 & 76.0 & -33.2 & 25.8 & -27.0 & 10.1 & -34.1 & 0.8 & 239.3 & 1228.6 & 449.0 & -179.4 & -92.9 & 1713.7 & 9552.9 \\
\hline Petrolina & 517.8 & 557.3 & 178.5 & -7.6 & -9.3 & 305.9 & 445.1 & 468.5 & 1.7 & -44.4 & -471.1 & -550.7 & -43.3 & 667.7 & 1117.1 & 10269.5 \\
\hline Vale do Ipojuca & -233.9 & 111.2 & 89.5 & 2285. & -1.0 & -15.6 & 484.2 & 5.7 & 166.6 & -106.1 & 3379.5 & -766.9 & 2117. & 795.9 & 7051.2 & 41885.5 \\
\hline Alto Capibaribe & 27.9 & 1.8 & 64.3 & -31.2 & -15.2 & 10.0 & -21.9 & -15.1 & 220.7 & 3698. & 2614.0 & -136.4 & 644.3 & -85.1 & 6977.5 & 17813.1 \\
\hline Mata Setentrional & -98.6 & -8.6 & 234.7 & -259.3 & -160.7 & 72.4 & -30.2 & -33.7 & -152.0 & 2230. & -1628.9 & -764.8 & -2525. & 350.5 & -3835.6 & -2000.0 \\
\hline $\begin{array}{l}\text { Vitória de Santo } \\
\text { Antão }\end{array}$ & 11.2 & -58.5 & 323.6 & -49.1 & -30.0 & -40.3 & -23.5 & 198.9 & -18.7 & 220.2 & 6193.7 & -230.4 & 1404. & -446.2 & 7737.5 & 18249.1 \\
\hline Mata Meridional & -254.4 & 46.4 & 141304. & 6248. & -103.4 & -12.8 & 87.0 & 60.9 & 1.4 & 1323. & -2019.2 & -1525.0 & -1160. & -1769.9 & 144238. & 162051.5 \\
\hline Recife & -140.1 & -4925. & -1881. & -1802. & -627.5 & -1653.2 & -351.5 & -981.3 & -969.8 & -2473 & -14697. & -13202. & -5864. & -22698. & -48669 & -190598.7 \\
\hline Suape & -54.1 & 4152. & 91.8 & 3662. & -66.9 & 588.4 & -23.1 & 351.3 & -144.3 & 93.6 & -499.6 & 1164.2 & 812.7 & -1187.4 & 9933.0 & 56737.4 \\
\hline \multicolumn{17}{|l|}{ ALAGOAS } \\
\hline Mata Alagoana & -143.4 & 1535. & -179.5 & 93.9 & -63.7 & -85.5 & 131.1 & 71.3 & -109.9 & 29437 & -869.1 & -571.6 & 584.9 & -573.0 & 31134.3 & 52989.5 \\
\hline Maceió & 4372. & -1525. & -494.3 & -266.6 & -276.2 & -496.8 & -156.0 & -386.6 & -471.7 & -482.2 & -51.1 & -2650.5 & 407.7 & 929.5 & -1751.5 & -40378.7 \\
\hline $\begin{array}{l}\text { São Miguel } \\
\text { dos Campos }\end{array}$ & 239.1 & -366.3 & 2413. & 12166 & 1882. & -134.5 & -181.3 & 323.9 & -219.3 & -375.5 & -1305.5 & -898.8 & 737.3 & -1465.4 & 15355.9 & 41489.3 \\
\hline
\end{tabular}

SERGIPE

\begin{tabular}{l|l|l|l|l|l|l|l|l|l|l|l|l|l|l|l|l}
\hline Aracaju & 5051. & -811.6 & -47.5 & 8370. & 2030. & -384.1 & -10.3 & 151.9 & -107.5 & 2499 & -2140.0 & -3319.1 & 8946. & -3106.5 & 19901.1 & 10573.8 \\
\hline
\end{tabular}
BAHIA

\begin{tabular}{|c|c|c|c|c|c|c|c|c|c|c|c|c|c|c|c|c|}
\hline Barreiras & 18.8 & 313.1 & 98.9 & 454.6 & -24.4 & -18.6 & 19.8 & 647.0 & 13.0 & 315.7 & 5047.7 & -219.1 & 759.3 & 2694.2 & 8016.8 & 60014.6 \\
\hline Juazeiro & -112.7 & -255.3 & 1361. & 796.7 & 263.8 & -53.1 & -40.9 & 14.4 & 2.2 & 319.6 & -484.1 & -517.1 & -878.3 & 638.3 & 582.8 & 23441.8 \\
\hline Bom J. da Lapa & 315.0 & 139.0 & 19.1 & -15.2 & -7.4 & -4.0 & -1.2 & -9.7 & 168.7 & -45.1 & 1064.8 & -66.2 & 379.9 & 339.1 & 2010.1 & 7735.0 \\
\hline Feira de Santana & 588.6 & -126.6 & 98.0 & 340.6 & 43288 & -120.4 & -126.5 & 64.3 & -111.0 & 336.4 & 2422.2 & 16899.2 & 2191. & 2439.1 & 68581.2 & 84946.8 \\
\hline $\begin{array}{l}\text { Santo Ant. } \\
\text { de Jesus }\end{array}$ & 18.4 & 47.9 & 55.9 & -115.7 & 2196. & -45.9 & 67.1 & -34.4 & -55.8 & 17055 & 2525.7 & 213243. & -1257 & 188.2 & 239237. & 244619.4 \\
\hline $\begin{array}{l}\text { Vitória da } \\
\text { Conquista }\end{array}$ & 106.9 & 137.1 & -70.8 & -106.1 & 888.4 & 1.6 & 629.8 & 29.5 & 327.2 & 608.2 & 7949.3 & 34389.1 & 2254 . & 111.7 & 117637. & 132174.6 \\
\hline Ilhéus-Itabuna & -510.9 & 16.2 & 1209. & 1256. & 4395. & 520.7 & -296.4 & -38.6 & 244.3 & -821.1 & 27069.3 & 169034. & -507.6 & -1742.0 & 202473. & 216652.5 \\
\hline Porto Seguro & -84.6 & 502.2 & 1660. & 389.9 & 1285. & -5.9 & -70.6 & 60.6 & 196.1 & 5742. & 9084.4 & 11362.7 & 2743. & 999.3 & 100388. & 138125.4 \\
\hline
\end{tabular}

Fonte: Elaboração própria com base nos dados da RAIS/MTE. 
Tabela B.4_Região Nordeste: caracterização das regiões por setor a partir do efeito alocação e seus componentes - 1995/2007

\begin{tabular}{|c|c|c|c|c|c|c|c|c|c|c|c|c|c|c|}
\hline & $\begin{array}{l}\text { Ext. } \\
\text { Min }\end{array}$ & $\begin{array}{l}\text { Não } \\
\text { met. }\end{array}$ & Met. & Mec & Ele. & $\begin{array}{c}\text { M. } \\
\text { Transp. }\end{array}$ & Madei. & Papel & Borr. & Quim. & Têxtil & Calç. & Alim. & $\begin{array}{l}\text { Antinua) } \\
\text { Agric. }\end{array}$ \\
\hline \multicolumn{15}{|l|}{ MARANHÃO } \\
\hline AU. São Luís & VC-NE & VC-NE & DC-E & VC-NE & VC-NE & DC-E & VC-NE & VC-NE & VC-NE & VC-NE & VC-NE & VC-NE & VC-NE & VC-NE \\
\hline Imperatriz & VC-NE & VC-E & VC-E & VC-NE & VC-NE & DC-E & DC-E & VC-NE & VC-E & VC-NE & VC-NE & VC-NE & VC-NE & VC-NE \\
\hline Gerais de Balsas & VC-E & VC-NE & VC-NE & VC-NE & VC-NE & VC-NE & VC-NE & VC-NE & VC-NE & VC-NE & VC-NE & VC-NE & VC-NE & VC-E \\
\hline
\end{tabular}

$$
\text { PIAUÍ }
$$

\begin{tabular}{|c|c|c|c|c|c|c|c|c|c|c|c|c|c|c|}
\hline Teresina & VC-NE & VC-NE & VC-NE & VC-NE & VC-NE & VC-NE & DC-E & VC-NE & DC-E & VC-NE & DC-E & VC-NE & VC-NE & VC-NE \\
\hline \multicolumn{15}{|l|}{ CEARÁ } \\
\hline Sobral & VC-NE & DC-E & VC-NE & VC-NE & VC-NE & VC-NE & VC-NE & VC-NE & VC-NE & VC-NE & DC-E & DC-E & VC-NE & VC-NE \\
\hline Fortaleza & VC-NE & VC-NE & DC-E & DC-E & DC-E & DC-E & DC-E & VC-E & VC-E & VC-E & VC-E & DC-E & VC-NE & VC-NE \\
\hline Pacajus & VC-NE & DC-E & VC-NE & DC-E & VC-NE & VC-NE & VC-NE & VC-E & VC-NE & DC-E & DC-E & VC-NE & VC-E & DC-E \\
\hline Litoral de Aracati & DC-E & DC-E & VC-NE & VC-NE & VC-NE & VC-NE & DC-E & VC-NE & VC-NE & VC-NE & VC-NE & VC-NE & VC-NE & VC-E \\
\hline Baixo Jaguaribe & DC-E & VC-E & VC-NE & VC-NE & VC-NE & VC-NE & VC-NE & VC-NE & VC-NE & VC-NE & VC-NE & VC-NE & VC-NE & VC-E \\
\hline Cariri & DC-E & VC-E & VC-E & VC-NE & VC-NE & VC-NE & DC-E & VC-NE & VC-E & VC-NE & VC-NE & VC-E & DC-E & VC-NE \\
\hline
\end{tabular}

RIO GRANDE DO NORTE

\begin{tabular}{l|c|c|c|c|c|c|c|c|c|c|c|c|c|c|c}
\hline Mossoró & VC-E & DC-E & VC-NE & VC-NE & VC-NE & VC-NE & VC-NE & VC-NE & VC-NE & VC-E & VC-NE & VC-NE & DC-E & DC-E \\
\hline Vale do Açu & VC-E & DC-E & VC-NE & VC-NE & VC-NE & VC-NE & VC-NE & VC-NE & VC-NE & VC-NE & VC-NE & VC-NE & VC-NE & VC-E \\
\hline Seridó Ocidental & VC-NE & DC-E & VC-NE & VC-NE & VC-NE & VC-NE & VC-NE & VC-NE & DC-E & VC-NE & VC-NE & DC-E & VC-NE & VC-NE \\
\hline Macaíba & DC-E & DC-E & VC-NE & VC-NE & VC-NE & VC-NE & VC-NE & DC-E & DC-E & VC-E & VC-E & VC-NE & DC-E & VC-NE \\
\hline Natal & DC-E & VC-NE & VC-NE & DC-E & VC-NE & VC-NE & VC-NE & VC-NE & VC-NE & VC-NE & VC-E & VC-NE & VC-NE & VC-NE \\
\hline
\end{tabular}

\section{PARAÍBA}

\begin{tabular}{l|l|l|l|l|l|l|l|l|l|l|l|l|l|l}
\hline Catolé da Rocha & VC-NE & VC-NE & VC-NE & VC-NE & VC-NE & VC-NE & VC-NE & VC-NE & VC-NE & VC-NE & VC-NE & VC-NE & VC-NE & VC-NE \\
\hline Souza & VC-NE & VC-NE & VC-NE & VC-NE & VC-NE & VC-NE & VC-NE & VC-NE & VC-NE & VC-E & VC-NE & VC-NE & VC-NE & VC-NE \\
\hline Campina Grande & VC-NE & DC-E & DC-E & DC-E & DC-E & VC-NE & VC-NE & VC-E & VC-E & VC-E & DC-E & VC-E & VC-NE & VC-NE \\
\hline João Pessoa & VC-NE & VC-NE & VC-NE & VC-NE & VC-NE & VC-NE & VC-NE & DC-E & DC-E & VC-NE & DC-E & DC-E & VC-NE & VC-NE \\
\hline
\end{tabular}


Tabela B.4_ Região Nordeste: caracterização das regiões por setor a partir do efeito alocação e seus componentes - 1995/2007

(conclusão)

\begin{tabular}{|c|c|c|c|c|c|c|c|c|c|c|c|c|c|c|}
\hline & $\begin{array}{l}\text { Ext. } \\
\text { Min }\end{array}$ & $\begin{array}{l}\text { Nẫo } \\
\text { met. }\end{array}$ & Met. & Mec & Ele. & $\begin{array}{c}\text { M. } \\
\text { Transp. }\end{array}$ & Madei. & Papel & Borr. & Quim. & Têxtil & Calç. & Alim. & Agric. \\
\hline \multicolumn{15}{|l|}{ PERNAMBUCO } \\
\hline Araripina & DC-E & DC-E & VC-NE & DC-E & VC-NE & VC-NE & VC-NE & VC-NE & VC-NE & VC-NE & VC-NE & VC-NE & VC-NE & VC-NE \\
\hline Petrolina & VC-NE & VC-NE & VC-NE & VC-NE & VC-NE & VC-NE & VC-NE & VC-NE & VC-E & VC-NE & VC-NE & VC-NE & VC-NE & VC-E \\
\hline Vale do Ipojuca & VC-NE & VC-E & VC-NE & VC-NE & DC-E & DC-E & VC-NE & VC-E & VC-E & DC-E & VC-E & VC-NE & VC-NE & VC-NE \\
\hline Alto Capibaribe & VC-NE & VC-E & VC-NE & VC-NE & VC-NE & VC-NE & VC-NE & VC-NE & VC-NE & VC-NE & VC-E & VC-NE & VC-NE & VC-NE \\
\hline Mata Setentrional & VC-NE & DC-E & VC-NE & DC-E & VC-NE & VC-NE & VC-NE & DC-E & VC-NE & VC-NE & VC-NE & DC-E & DC-E & VC-E \\
\hline $\begin{array}{l}\text { Vitória de Santo } \\
\text { Antão }\end{array}$ & VC-NE & DC-E & VC-NE & VC-NE & VC-NE & VC-NE & DC-E & VC-NE & VC-NE & VC-NE & VC-NE & VC-NE & VC-E & DC-E \\
\hline Mata Meridional & VC-NE & VC-NE & VC-NE & VC-NE & DC-E & VC-NE & VC-NE & VC-NE & VC-NE & VC-NE & VC-NE & VC-NE & DC-E & DC-E \\
\hline Recife & VC-NE & VC-NE & DC-E & DC-E & DC-E & DC-E & VC-NE & DC-E & VC-NE & DC-E & DC-E & VC-NE & VC-NE & VC-NE \\
\hline Suape & VC-NE & VC-NE & VC-E & VC-NE & DC-E & VC-NE & DC-E & VC-NE & VC-NE & VC-E & DC-E & VC-NE & VC-E & DC-E \\
\hline \multicolumn{15}{|l|}{ ALAGOAS } \\
\hline Mata Alagoana & DC-E & VC-NE & VC-NE & VC-NE & VC-NE & VC-NE & VC-NE & VC-NE & VC-NE & VC-NE & VC-NE & VC-NE & VC-E & DC-E \\
\hline Maceió & VC-NE & VC-NE & VC-NE & VC-NE & VC-NE & DC-E & VC-NE & VC-NE & VC-NE & VC-NE & VC-NE & VC-NE & VC-E & VC-NE \\
\hline $\begin{array}{l}\text { São Miguel dos } \\
\text { Campos }\end{array}$ & VC-NE & VC-NE & VC-NE & VC-NE & VC-NE & VC-NE & VC-NE & VC-NE & VC-NE & VC-NE & VC-NE & VC-NE & VC-E & DC-E \\
\hline \multicolumn{15}{|l|}{ SERGIPE } \\
\hline Aracaju & VC-NE & DC-E & VC-NE & VC-NE & VC-NE & DC-E & VC-NE & VC-NE & VC-NE & VC-NE & DC-E & VC-NE & VC-NE & VC-NE \\
\hline
\end{tabular}

BAHIA

\begin{tabular}{|c|c|c|c|c|c|c|c|c|c|c|c|c|c|c|}
\hline Barreiras & VC-NE & VC-NE & VC-E & VC-NE & VC-NE & DC-E & VC-NE & VC-NE & VC-E & VC-NE & VC-NE & VC-NE & VC-E & VC-E \\
\hline Juazeiro & DC-E & VC-NE & VC-NE & VC-NE & VC-NE & DC-E & VC-NE & VC-NE & VC-E & VC-NE & VC-NE & VC-NE & DC-E & VC-E \\
\hline Bom J. da Lapa & VC-NE & VC-NE & VC-NE & VC-NE & VC-NE & VC-NE & VC-NE & VC-NE & VC-NE & DC-E & VC-NE & VC-NE & VC-NE & VC-E \\
\hline Feira de Santana & VC-NE & DC-E & VC-E & VC-NE & VC-NE & DC-E & DC-E & VC-E & DC-E & VC-E & VC-NE & VC-NE & VC-NE & VC-NE \\
\hline $\begin{array}{l}\text { Santo Antônio } \\
\text { de Jesus }\end{array}$ & VC-NE & VC-NE & VC-E & DC-E & VC-NE & VC-NE & VC-E & DC-E & DC-E & VC-NE & VC-NE & VC-NE & DC-E & VC-E \\
\hline Salvador & VC-NE & VC-NE & DC-E & VC-NE & VC-NE & VC-NE & VC-NE & DC-E & VC-NE & DC-E & VC-NE & VC-NE & VC-NE & VC-NE \\
\hline $\begin{array}{l}\text { Vitória da } \\
\text { Conquista }\end{array}$ & VC-NE & VC-NE & DC-E & DC-E & VC-NE & VC-E & VC-NE & VC-NE & VC-NE & VC-NE & VC-NE & VC-NE & VC-NE & VC-E \\
\hline Ilhéus-Itabuna & DC-E & VC-NE & VC-NE & VC-NE & VC-NE & VC-NE & DC-E & VC-NE & VC-E & VC-NE & VC-NE & VC-NE & VC-NE & DC-E \\
\hline Porto Seguro & VC-NE & VC-NE. & VC-NE & VC-E & VC-NE & VC-NE & DC-E & VC-E & VC-NE. & VC-NE. & VC-NE & VC-NE & VC-NE & VC-E \\
\hline
\end{tabular}

(VC-E) Vantagem Competitiva, especializada; (VC-NE) Vantagem Competitiva, não especializada; (DC-E) Desvantagem Competitiva, especializada;

(DC-NE) Desvantagem Competitiva, não especializada.

Fonte: Elaboração própria com base nos dados da RAIS/MTE. 